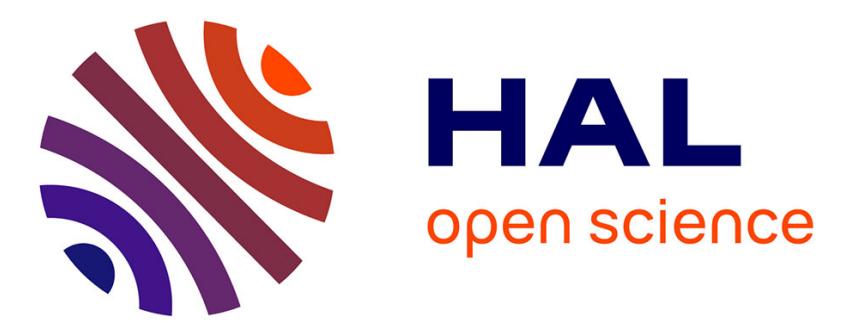

\title{
NO formation in high pressure premixed flames: Experimental results and validation of a new revised reaction mechanism
}

Stéphanie de Persis, Laure Pillier, Mahmoud Idir, Julien Molet, Nathalie Lamoureux, Pascale Desgroux

\section{To cite this version:}

Stéphanie de Persis, Laure Pillier, Mahmoud Idir, Julien Molet, Nathalie Lamoureux, et al.. NO formation in high pressure premixed flames: Experimental results and validation of a new revised reaction mechanism. Fuel, 2020, 260, pp.116331. 10.1016/j.fuel.2019.116331 • hal-02375726

\author{
HAL Id: hal-02375726 \\ https://hal.science/hal-02375726
}

Submitted on 13 Nov 2020

HAL is a multi-disciplinary open access archive for the deposit and dissemination of scientific research documents, whether they are published or not. The documents may come from teaching and research institutions in France or abroad, or from public or private research centers.
L'archive ouverte pluridisciplinaire HAL, est destinée au dépôt et à la diffusion de documents scientifiques de niveau recherche, publiés ou non, émanant des établissements d'enseignement et de recherche français ou étrangers, des laboratoires publics ou privés. 
NO formation in high pressure premixed flames: experimental results and validation of a new revised reaction mechanism

Stéphanie de Persis ${ }^{1,2^{*}}$, Laure Pillier ${ }^{3}$, Mahmoud $\operatorname{Idir}^{1}$, Julien Molet ${ }^{1,2}$, Nathalie Lamoureux ${ }^{3}$, Pascale Desgroux ${ }^{3}$

Affiliations

${ }^{1}$ ICARE, Institut de Combustion, Aérothermique, Réactivité, Environnement, UPR3021 CNRS, 1C Av. de la recherche scientifique, 45071 Orléans, France

${ }^{2}$ Université d'Orléans, Château de la source, Avenue du parc floral, 45067 Orléans, France

${ }^{3}$ Université Lille, CNRS, UMR8522 - PC2A - PhysicoChimie des Processus de Combustion et de l'Atmosphère, F-59000 Lille, France

*Corresponding author: S. de Persis, depersis@cnrs-orleans.fr 


\begin{abstract}
This paper presents an experimental and modelling study of NO formation in high pressure premixed flames. Experiments were performed in a high-pressure counterflow burner in which laminar premixed $\mathrm{CH}_{4} /$ air flames were stabilised at equivalence ratios of $\mathrm{E} . \mathrm{R}=0.7,1$ and 1.2 and for pressures varying from 0.1 to $0.7 \mathrm{MPa}$. We report quantitative NO mole fraction profiles measured by Laser Induced Fluorescence. The effects of pressure and equivalence ratio on NO formation are discussed. These results are compared to the simulations using two reaction mechanisms: NOmecha2.0 associated to a detailed mechanism for methane oxidation: GDFkin ${ }^{\circledR} 3.0$ and the mechanism from Klippenstein et al., which is the most recent high-pressure NOx formation mechanism available in the literature. In general, both mechanisms are able to predict NO correctly in lean and stoichiometric high pressure flames; however, in rich flames, GDFkin ${ }^{\circledR} 3.0 \_$NOmecha2.0 gives the best predictions. The performances of these mechanisms are also tested on NO measurements in high-pressure flames from the literature. A kinetic analysis is then presented to identify the main pathways that lead to the formation and consumption of NO and highlight the differences between the two mechanisms, as well as a sensitivity analysis to identify important reactions that influence the formation/consumption of NO in our high pressure flames.
\end{abstract}

\title{
Keywords:
}

NOx formation, high pressure flames, Laser Induced Fluorescence, methane combustion, kinetic analysis 


\section{Introduction}

Nitric oxide (NO) is a pollutant emitted by all practical combustion devices. Since NO emissions are regulated, there is a need to understand how NO is formed in order to control the emissions, in particular at high pressure, encountered in most of the existing combustion applications (power-generation and propulsion engines). The investigation of NO formation kinetics in high-pressure flames is therefore a research area of great practical interest. The main formation paths of NO in flames have been identified: the thermal-NO [1], the prompt-NO [2], the $\mathrm{NNH}$ [3] and the $\mathrm{N}_{2} \mathrm{O}$ [4] routes. Since the beginning of this century, particular attention was paid to the prompt-NO formation as it has been demonstrated that the initiation reaction $\mathrm{CH}+\mathrm{N}_{2}=\mathrm{HCN}+\mathrm{N}$ (known to be spin forbidden) has to be replaced by the reaction $\mathrm{CH}+\mathrm{N}_{2}$ $=\mathrm{NCN}+\mathrm{H}[5,6]$. In 2006, El Bakali et al. [7] were the first to implement the new initiation reaction in their mechanism, namely the GDFkin ${ }^{\circledR} 3.0 \_N C N$ (i.e., the hydrocarbon oxidation mechanism GDFkin ${ }^{\circledR} 3.0$ associated to the N-species sub-mechanism NOmecha1.0). Since then, Lamoureux et al. have performed an extensive experimental and numerical study on the role of $\mathrm{NCN}$ in the prompt-NO mechanism in low pressure methane and acetylene flames with the measurements of species such as $\mathrm{CH}, \mathrm{NO}, \mathrm{NCN}$ [8-10], $\mathrm{HCN}, \mathrm{CN}[11,12]$ and $\mathrm{NCO}[13]$ combining LIF (Laser Induced Fluorescence) and CRDS (Cavity Ring Down Spectroscopy) techniques. Recently, Lamoureux et al. [14] proposed a final version of a new detailed NOx chemistry sub-mechanism, named NOmecha2.0, validated at high temperature on a large experimental database obtained in laminar premixed flames, jet-stirred and plug-flow reactors under sub-atmospheric and atmospheric pressure conditions. The purpose of the present paper is to validate NOmecha2.0 in high pressure flames. Very recently, Klippenstein et al. [15] proposed an optimized mechanism for modelling of prompt-NO formation in high pressure flames using high level theoretical methods. This mechanism is the most recent updated NOx mechanism in the literature and is based on previous work of the group [16-19]. Interestingly, 
they highlighted the importance of the branching ratios for the reaction $\mathrm{NCN}+\mathrm{H} \rightarrow$ products, especially at high pressure, but this mechanism was validated only on results from Klassen et al. [20] in laminar premixed $\mathrm{CH}_{4} / \mathrm{O}_{2} / \mathrm{N}_{2}$ flat flames at pressures ranging from 1 to 14.6 atm.

The complete understanding of the chemical kinetics involved in the production of NO at high pressure requires accurate in situ measurements of NO concentration. Most of the studies dedicated to NO measurements in laminar high pressure flames were performed using Laser Induced Fluorescence by the groups of N.M. Laurendeau [20-30] and R.K. Hanson [31-35]. The studies performed in Laurendeau's group were dedicated to the kinetics of NO formation in laminar high pressure flames. Thomsen et al. [21,22] presented NO LIF measurements in lean (equivalence ratio E.R. from 0.5 to 0.8 ) premixed $\mathrm{CH}_{4} / \mathrm{O}_{2} / \mathrm{N}_{2}$ flat flames at pressures from 1 to 14.6 atm and a comparison [22] with modeling results obtained with the GRIMech2.11 mechanism. The first NO LIF measurements in a counterflow burner configuration were performed by Thomsen et al. $[23,24]$ who presented an experimental and modeling study of NO formation in premixed $\mathrm{CH}_{4}$ /air flames at equivalence ratios varying from 0.65 to 1.5 at atmospheric and high pressures. Further studies were performed in high pressure partially premixed and diffusion flames [25-30].

The studies performed in Hanson's group [31-35] were more focused on spectroscopic considerations to measure NO by PLIF (Planar Laser Induced Fluorescence) imaging in a highpressure environment. Di Rosa et al. [31] presented an experimental and theoretical study of the excitation/detection spectra of NO LIF and interferences by $\mathrm{O}_{2}$ LIF in the burned gases of high-pressure (0.1-1MPa) lean $\mathrm{CH}_{4} / \mathrm{O}_{2} / \mathrm{N}_{2}$ non premixed flat flames. The authors proposed a method to correct the LIF NO signals from the $\mathrm{O}_{2}$ LIF contribution by collecting the fluorescence signal on two different spectral windows. Bessler et al. [35] performed a comparative study, based on their previous work [32-34], of the possible excitation/detection schemes using the vibrational bands $\mathrm{A}-\mathrm{X}(0,0), \mathrm{A}-\mathrm{X}(0,1)$ and $\mathrm{A}-\mathrm{X}(0,2)$ for NO LIF 
measurements in the burned gases of flat $\mathrm{CH}_{4} /$ air premixed flames stabilized at high pressure (0.1-6 MPa).

Recently, the group of J.M. Bergthorson [36-38] presented NO and CH LIF measurements in premixed jet wall stagnation alkanes and alcohols flames at atmospheric pressure. The experimental results were compared with modelling using different kinetic mechanisms and analyses were performed to highlight $\mathrm{CH}$ and $\mathrm{NO}$ formation pathways in these different flames. More recently, the same group [39] published LIF NO measurements in high pressure lean methane-air stagnation flames $(\mathrm{P}=0.2,0.4$ and $0.8 \mathrm{MPa})$, with a modelling study using the NUIG mechanism [40]. Bohon et al. [41,42] also studied NO formation in alcohol and alkanes premixed flames at atmospheric pressure. Zhou et al. [43] investigated the effect of $\mathrm{CH}_{4}$ content in syngas flames on NO formation in a premixed flat flame burner at atmospheric pressure.

In this work, we present new experimental results of NO profile measurements obtained by LIF in high pressure laminar premixed counterflow methane/air flames. The measurements in stoichiometric and rich (Equivalence Ratio E.R.=1.2) high pressure (from 0.1 to $0.7 \mathrm{MPa}$ ) flames presented here, in addition to our results in lean flames (E.R.=0.7) published in [44], supplement and extend the experimental database on NO measurements in high pressure counterflow flames available in the literature. Note that in $[23,24]$, the pressure limit is $0.5 \mathrm{MPa}$ for the lean $(E . R .=0.65)$ flames, no stoichiometric flame and only one rich $(E . R .=1.4)$ flame at pressures higher than $0.1 \mathrm{MPa}$ are presented in the counterflow configuration.

The performance of the NOx submechanism, NOmecha2.0 [14], in the prediction of NO at high pressure is discussed in this paper and it is compared to the new mechanism from Klippenstein et al. [15] using the LOGEsoft software [45]. For that purpose, NOmecha2.0 is associated to GDFkin ${ }^{\circledR} 3.0$ [46]. The low-pressure version of the GDFkin ${ }^{\circledR} 3.0$ hydrocarbon mechanism was adopted in [14], its high pressure version [46] is adopted in the present work. A kinetic analysis 
performed by rate-of-consumption/production, net flux and sensitivity analysis is then presented and discussed to compare the mechanisms.

\section{$\underline{\text { 2. Experimental }}$}

The experimental facility used in this work, including the high-pressure burner and the LIF system, has been detailed previously in $[44,47,48]$. An overview is presented here.

\subsection{High pressure burner and flame conditions}

The high-pressure burner consists of two twin counterflow converging burners placed in a high pressure vessel, equipped with optical accesses. Each burner is composed of two co-annular nozzles of $7 \mathrm{~mm}$ and $13 \mathrm{~mm}$ diameters, which were aerodynamically shaped to obtain a uniform velocity profile at their exit. The distance between the burners is fixed at $10 \mathrm{~mm}$. A nitrogen co-flow isolates the flame from the surrounding gases. The burners are cooled by water circulation at a fixed temperature between 30 and $50^{\circ} \mathrm{C}$ depending on the flame conditions, to avoid water condensation on their surfaces. The pressure within the vessel is regulated with a pressure transducer and a control valve. Gas flows are monitored by Brooks mass flowmeters through a Labview program. Figure 1 shows pictures of the $\mathrm{CH}_{4}$ /air flames stabilised in this work: for E.R. $=0.7$ at pressures from $\mathrm{P}=0.1$ to $0.7 \mathrm{MPa}$; for $\mathrm{E} . \mathrm{R} .=1.0$ at pressures $\mathrm{P}=0.1$ and 0.3 MPa and for E.R.= 1.2 at pressures from $\mathrm{P}=0.1$ to $0.5 \mathrm{MPa}$.

A stabilisation criterion was defined, using a telescopic sight with high magnification (allowing to distinguish a wire of $50 \mu \mathrm{m}$ ), placed on one of the visualisation window of the chamber in order to scrutinise the flamefronts. For each pressure condition, flames were considered as stable if their central shape appear flat in a diameter greater than the nozzle diameter $(7 \mathrm{~mm})$, 
and their position above the burner do not fluctuate by more than $+/-50 \mu \mathrm{m}$ around their average position.

Flame conditions are summarised in Table 1. Under certain flame conditions, the gas velocity ratio between the upper and lower burners had to be adjusted to keep the flames well centered between the burners. This ratio is denoted $\beta$ in Table 1 . Laminar premixed $\mathrm{CH}_{4} /$ air flames were studied in this work, with equivalence ratios E.R. $=0.7$ (already published in [44]); 1 and 1.2 and the pressure was varied from 0.1 to $0.7 \mathrm{MPa}$, depending on flame stability. Note that the stoichiometric flames could not be stabilized at a pressure higher than $0.3 \mathrm{MPa}$ and the rich flame higher than $0.5 \mathrm{MPa}$ because of instabilities. Such instability problems were also mentioned in studies of counterflow premixed $\mathrm{CH}_{4} /$ air flames by Laurendeau's group [23].

\subsection{Laser Induced Fluorescence measurements}

For the LIF measurements of NO in the A-X $(0,0)$ vibrational band, the wavelength around 226 $\mathrm{nm}$ was obtained by mixing the frequency-doubled output of a dye laser (Quantel TDL+, mixture of Rhodamine 590 and 610) with the residual infrared radiation from the pumping injection seeded Nd-YAG laser (Quantel Brillant B, repetition rate $10 \mathrm{~Hz}, 6 \mathrm{~ns}$ pulses, linewidth $\left.0.06 \mathrm{~cm}^{-1}\right)$. The laser energy was reduced to $100 \mu \mathrm{J}$ to perform LIF measurements in the linear regime. The beam was focused at the centre of the burner and the fluorescence signal was collected at right angle through a spectrometer and a photomultiplier. The probed volume was $160 \mu \mathrm{m}$ in height and $6.4 \mathrm{~mm}$ in width.

As demonstrated in our previous work [44], the LIF excitation through the $\mathrm{P}_{1}(23,5)$, $\mathrm{Q}_{1}+\mathrm{P}_{21}(14,5), \mathrm{Q}_{2}+\mathrm{R}_{12}(20,5)$ lines $(\lambda=226.03 \mathrm{~nm})$ in the A-X $(0,0)$ vibrational band and the LIF signal collection through the $\mathrm{A}-\mathrm{X}(0,1)$ band (centred at $236 \mathrm{~nm}$ with a $2.8 \mathrm{~nm}$ bandpass) was the best compromise to maximise the NO LIF signal and minimise the interferences in our flame conditions. The NO LIF signal was analysed with the same procedure as in [44], the 
spectral overlap function, the fluorescence quantum yield and the Boltzmann fraction were calculated along each flame and variations of those three parameters were found negligible at a given pressure. A calibration procedure was then applied in each flame, consisting in doping the flame with known small amounts of NO to perform a calibration plot. The experimental uncertainties reached $\pm 20 \%$ for all flames. This value takes into account the following uncertainties: i) uncertainties on the calibration procedure (around $\pm 10 \%$ ); ii) uncertainties on the mass flow meters (implying uncertainties on the equivalence ratio and dilution ratio); iii) uncertainties on the probe volume position; iv) uncertainties on the flame temperature (estimated to be equal to the adiabatic flame with an uncertainty of $\pm 5 \%$ ); v) the uncertainty on pressure inside the combustion chamber $( \pm 1 \%)$.

\section{Modelling}

\subsection{Code}

The kinetic modelling of atmospheric and high-pressure counterflow flames was carried out using the LOGEsoft software (LOGEresearch v1.10.0 [45]) with the counterflow flame module. Calculations were performed by solving the energy equation in the case of an adiabatic and isobaric system and thermo-diffusion effects were taken into account. The adaptive mesh parameters GRAD and CURV were fixed to 1.0 and 1.5 respectively in LOGEsoft, with a number of 300 grid points.

The calculated NO mole fraction profiles with and without considering the radiation heat loss were carried out, assuming optically thin radiation originating from the major species $\left(\mathrm{CO}_{2}\right.$ and $\mathrm{H}_{2} \mathrm{O}$ ) within the flame. According to Gore et al. [49], the optically thin limit assumption, which involves considering only the loss by emission (no reabsorption), is adequate for stable flames with moderately high strain rates away from the radiative extinction limits, which is our case. Moreover, as mentioned by Bhattacharjee and Grosshandler [50], the importance of radiation 
can be estimated by performing the computation twice: first without radiation and then with the optically thin model. This technique, applied in our case, gives an upper bound to the effect of radiation on the flow field. The results (see supplementary file, Table A) show a weak influence $(<10 \%)$ on the temperature and NO mole fraction, for all the flame conditions. As already observed in [48] for $\mathrm{OH}$, the variations with and without radiation are below our experimental uncertainties on the NO mole fraction $( \pm 20 \%)$. As a consequence, radiation effects were neglected in our flames.

\subsection{Reaction mechanisms}

The experimental NO mole fraction profiles were compared to the simulated ones obtained with two detailed kinetic mechanisms: GDFkin ${ }^{\circledR} 3.0$ associated to NOmecha2.0 [14], named GDFkin ${ }^{\circledR} 3.0 \_$NOmecha2.0, developed by our group; and the mechanism from Klippenstein et al. [15], named here Klippenstein mechanism.

The thermodynamic and transport properties files provided with each mechanism were employed. The GDFkin ${ }^{\circledR} 3.0$ mechanism (available in [14]) has been largely employed at low and atmospheric pressure $[7-14,46,51]$. In order to use this mechanism at high pressure (or atmospheric pressure), it is necessary to modify a few reactions whose rate constants are pressure-dependent. Those reactions and the full mechanism are given in the supplementary files (Table B, GDFnomecha20HP.inp and GDFnomecha20HPtran.dat).

The NOmecha2.0 submechanism is given as a supplementary file in [14] for low pressure flame conditions. But two reactions need to be modified before using it at high pressure: $\mathrm{HCNO}=\mathrm{HCN}+\mathrm{O}$ and $\mathrm{H}+\mathrm{NCN}=\mathrm{HNCN}$. Their corresponding high pressure rate constants are also listed in Table B in the supplementary files. Finally, some pressure-dependent reactions were updated with a fall-off formulation of their rate constants; these reactions are given in [14]. The GDFkin ${ }^{\circledR} 3.0 \_N O m e c h a 2.0$ mechanism contains 119 species involved in 883 
reversible reactions. In this work, in order to reduce the calculation time and convergence problems, this mechanism was truncated to the oxidation of $\mathrm{C} 1$ to $\mathrm{C} 3$ hydrocarbons $(+\mathrm{NOx}$ chemistry), suitable for methane combustion. The good reproducibility of the simulated results performed with the complete and with the simplified mechanisms was checked.

The Klippenstein mechanism [15] is the most recent updated mechanism developed to predict the NO formation in high pressure flames. This mechanism is based on previous work of the group [16-19] and was updated in [15]. In this work, the NCN thermochemistry and reactions rates for $\mathrm{CH}+\mathrm{N}_{2} \rightarrow \mathrm{NCN}+\mathrm{H}, \mathrm{NCN}+\mathrm{H} \rightarrow$ products, and $\mathrm{NCN}+\mathrm{OH} \rightarrow$ products were reevaluated by high level theoretical methods. The pressure dependency of the reactions NCN $+\mathrm{H} \rightarrow$ products was investigated. The resulted mechanism was validated by comparison with results from laminar premixed $\mathrm{CH}_{4} / \mathrm{O}_{2} / \mathrm{N}_{2}$ flat flames at pressures ranging 1-14.6 atm, reported by Klassen [20]. The Klippenstein mechanism contains 148 species involved in 2692 reactions. Table 2 compares the NO formation sub-mechanisms (reactions and associated rate constants calculated at 2000K) included in the two mechanisms (GDFkin®3.0_NOmecha2.0 [14] and Klippenstein [15]). The sub-mechanisms of $\mathrm{NO}$ formation by thermal, prompt, $\mathrm{NNH}$ and $\mathrm{N}_{2} \mathrm{O}$ pathways are included in both sub-mechanisms. The thermal and NNH reaction mechanisms are identical in both mechanisms. The $\mathrm{N}_{2} \mathrm{O}$ reaction pathways are identical in both mechanisms (same reactions) but the rate constant values are different. For the prompt-NO pathway and the NCN chemistry, significant differences are observed in terms of reactions and rate constants, particularly for the description of the chemistry of NCN.

The GDFkin ${ }^{\circledR} 3.0 \_N O m e c h a 2.0$ and Klippenstein mechanisms were validated against laminar $\mathrm{CH}_{4}$ /air flames velocities measurements at 0.1 and $0.5 \mathrm{MPa}$. Results are presented in Figure 2. A slight difference is observed between the two mechanisms with GDFkin ${ }^{\circledR} 3.0 \_$NOmecha2.0 giving systematically lower flame velocities values than Klippenstein, the difference is reduced when pressure increases. 
Figure A in the supplementary file shows the comparison between the temperature profiles predicted by GDFkin ${ }^{\circledR}$ 3.0_NOmecha2.0 and Klippenstein using the adiabatic assumption in all our flames conditions. Figure A clearly shows that both mechanisms predict similar temperature profiles (and maximum temperature values) whatever the pressure, only a slight difference is observed in some conditions (E.R.=0.7 and 1 at 0.1 and $0.7 \mathrm{MPa}$, and E.R.=1.2 at $0.1,0.3$ and $0.5 \mathrm{MPa}$ ) for which Klippenstein predicts a slightly larger temperature profile compared to GDFkin®3.0_NOmecha2.0. This can be due to small differences in the predictions of laminar flame velocities between the two mechanisms, as shown in the Figure 2. The maximum temperature increases slightly as pressure increases for the three equivalence ratio conditions (see Table 1) and it increases by about $400 \mathrm{~K}$ between lean and rich conditions and only decrease slightly in rich flames.

\subsection{Kinetic analyses}

The kinetic analyses carried out in this paper consisted in reaction pathways (rate-ofconsumption ROC/production ROP and net flux analyses) and sensitivity analyses. Rates of production and consumption as a function of the distance from the bottom burner were computed for each species with LOGESoft [45]. Net rates were considered by summing ROC and ROP after integration over the whole flame domain. It is thus possible to have global information on which reaction contributes to the production or consumption of a given species. To identify elementary reactions that dominate the formation/consumption of NO, sensitivity analyses were also conducted (only the 20 most contributive reactions were considered). 


\section{$\underline{\text { 4. Results and discussion }}$}

\subsection{Experimental results}

The experimental NO mole fraction profiles are presented in Figure 3 for all the $\mathrm{CH}_{4} /$ air counterflow flames conditions (E.R.= 0.7; 1 and $1.2-\mathrm{P}=0.1$ to $0.7 \mathrm{MPa})$. As mentioned earlier, the stoichiometric flame could not be stabilized at a pressure higher than $0.3 \mathrm{MPa}$ and the rich flame higher than 0.5 MPa because of instabilities. As shown in Figure 3, in the lean flames (E.R.=0.7), the maximum NO mole fraction remains almost constant when pressure increases from 0.1 to $0.7 \mathrm{MPa}$. In the stoichiometric flames, the maximum NO mole fraction increases by a factor of 2 between 0.1 and $0.3 \mathrm{MPa}$. For the rich flames, $\mathrm{X}(\mathrm{NO})_{\max }$ value increases linearly with pressure. Concerning the effect of the equivalence ratio, at atmospheric pressure, $\mathrm{X}(\mathrm{NO})_{\max }$ increases strongly between E.R. $=0.7$ and 1 (from $\sim 7 \mathrm{ppm}$ at E.R. $=0.7$ to $\sim 46 \mathrm{ppm}$ at E.R.=1) and it remains constant when the equivalence ratio is further increased to 1.2. At 0.3 $\mathrm{MPa}, \mathrm{X}(\mathrm{NO})_{\max }$ increases from $\sim 7 \mathrm{ppm}$ in lean flames to $\sim 90 \mathrm{ppm}$ in stoichiometric flames, it then decreases slightly in rich flames $(\sim 68 \mathrm{ppm})$.

\subsection{Comparison between experimental data and calculated NO mole fraction profiles}

Figure 4 compares the experimental and calculated NO mole fraction profiles with both mechanisms: Klippenstein [15] and GDFkin ${ }^{\circledR} 3.0 \_N O m e c h a 2.0$ [14], in all the studied $\mathrm{CH}_{4} /$ air flames. As shown in figure 4, NO profiles simulated with both mechanisms satisfactorily reproduce the experimental NO profile 'bell' shapes for all the pressure conditions, however some discrepancies are observed for the flamefront positions in the lean and rich flames, which could be attributed to:

1) buoyancy effect, as mentioned in [23], which can slightly compress the distance between the top and bottom flamefronts ; 
2) slight heating of the top burner by the burned gases released during combustion. This can have an impact on the unburned fresh gases temperature and on the flame speed. As described in [47], the importance of the heating of the top burner was previously evaluated and it was demonstrated that the variations observed in the $\mathrm{OH}$ mole fraction profiles are smaller than the experimental uncertainties;

3) the uncertainty on the location measurement is estimated to be $\pm 100 \mu \mathrm{m}$.

The comparison between experimental and calculated maximum $\mathrm{NO}$ mole fraction $\mathrm{X}(\mathrm{NO})_{\max }$ for the all the flames conditions is presented in Figure B in the supplementary files. In the lean flames, the experimental maximum NO mole fraction is nearly constant with the pressure increase. GDFkin ${ }^{\circledR} 3.0 \_$NOmecha2.0 predicts a slight increase of $\mathrm{X}(\mathrm{NO})_{\max }$ when pressure increases, with a slight overestimation at 0.5 and $0.7 \mathrm{MPa}$ compared to experiments. Klippenstein predicts an increase of $\mathrm{X}(\mathrm{NO})_{\max }$ between 0.1 to $0.3 \mathrm{MPa}$ and $\mathrm{X}(\mathrm{NO})_{\max }$ remains constant as pressure increases to 0.5 and $0.7 \mathrm{MPa}$. In the stoichiometric flames, the increase of $\mathrm{X}(\mathrm{NO})_{\max }$ by a factor of 2 between 0.1 and $0.3 \mathrm{MPa}$ is perfectly predicted by both mechanisms, which are in a perfect agreement with each other. In the rich flames, GDFkin ${ }^{\circledR} 3.0 \_$NOmecha2.0 is in good agreement with experimental results (within the error bars), as Klippenstein slightly underestimates the NO concentration for all pressures. An underprediction of NO by the mechanism of Klippenstein in rich conditions was also reported in low pressure methane flames [19].

In summary, both mechanisms present good predictions of NO in all the flames conditions presented here, with a slight better prediction of GDFkin ${ }^{\circledR} 3.0 \_$NOmecha2.0 in the rich flames. 


\section{fraction profiles}

In this section, experimental results obtained in high pressure flames by Thomsen et al. [23,24] and Naik et al. [27] are compared to simulations performed with GDFkin ${ }^{\circledR} 3.0 \_$NOmecha2.0 and Klippenstein. In order to evaluate the chemical kinetics of NO formation in advanced gas turbines, Thomsen et al. [21-24] measured (by LIF) NO concentrations in various premixed $\mathrm{CH}_{4} / \mathrm{O}_{2} / \mathrm{N}_{2}$ flat and counterflow flames. Here, we focused only on their lean $(\mathrm{E} . \mathrm{R} .=0.7)$ counterflow $\mathrm{CH}_{4} /$ air flames at $0.1,0.2,0.3$ and $0.4 \mathrm{MPa}[23,24]$ for comparison with our lean flames. Calculated and experimental NO profiles in these flames are presented in the supplementary files (Figure C). An overall good agreement is observed between experiments and modelling for all pressures, except at $0.4 \mathrm{MPa}$ where the flamefronts position is not well predicted by both mechanisms. At $\mathrm{P}=0.4 \mathrm{MPa}$, the flamefront seems to broaden out. Thomsen et al. [23] explain that at high pressure the flamefronts begin to become wrinkled, leading to non-uniformities at the burner exit. Measurements across these flamefronts are averaged across the wrinkles, resulting in a wider and more gradual increase in NO formation.

Figure 5 compares the experimental and calculated peak NO mole fraction in the lean counterflow flames of Thomsen et al. [23,24]. It shows that, as for our lean (same E.R.=0.7) counterflow $\mathrm{CH}_{4} /$ air flames, the experimental peak NO concentration is nearly constant when pressure increases. GDFkin ${ }^{\circledR} 3.0 \_$NOmecha2.0 predicts a slight increase with pressure, while Klippenstein predicts a slight increase between 0.1 and $0.2 \mathrm{MPa}$ and then a slight decrease as pressure increases, but both simulation results are close to each other and within the experimental error bars reported in [23,24].

The predictions of both mechanisms were also compared to results obtained by Naik et al. [27] in partially premixed $\mathrm{CH}_{4} / \mathrm{O}_{2} / \mathrm{N}_{2}$ high pressure counterflow flames, where $\mathrm{NO}$ mole fraction profiles were measured by LIF. Results are presented in Figure 6 for an equivalence ratio of 
1.45 at $0.1 \mathrm{MPa}$ (Figure 6a), 0.3 MPa (Figure 6b) and 0.6 MPa (Figure 6c). Both mechanisms give closed results but slightly underestimate the NO mole fraction at $0.1 \mathrm{MPa}$ and overestimate it at 0.3 and $0.6 \mathrm{MPa}$.

\subsection{Kinetic analyses}

In order to compare the two mechanisms regarding their predictions of NO in our flames conditions, a kinetic analysis is presented below based on reaction pathways and sensitivity analysis.

\section{b-1) Reaction pathways}

First, net rates were considered for the N-species by summing the rates of consumption (ROC, negative values) and rates of production (ROP, positive values) integrated over the whole flame domain (distance from the bottom burner $=0$ to $1 \mathrm{~cm}$ ). Figure $\mathrm{D}$ in the supplementary files shows the net rate diagram drawn for GDFkin ${ }^{\circledR} 3.0 \_$NOmecha2.0 (Figure D1) and Klippenstein (Figure D2) for E.R.=0.7 at $0.1 \mathrm{MPa}$. For clarity reasons, net rates are expressed in $\%$ and the diagram was simplified by removing negligible pathways $(<10 \%)$. It clearly shows the complexity of the chemical structure of the $\mathrm{N}$-species mechanism: it is very difficult to obtain directly the contribution to the overall NO formation by only removing each of the four major routes (prompt, thermal, $\mathrm{NNH}$ and $\mathrm{N}_{2} \mathrm{O}$ ) because of crossed pathways as mentioned in [41, 44]. It is however possible to compare how the main precursor of NO, i.e. $\mathrm{N}_{2}$, decomposes through the four major pathways. Figure 7 shows the net rates of consumption of $\mathrm{N}_{2}$ in terms of percentages for both mechanisms in all the conditions studied in this paper.

In lean flames $($ E.R. $=0.7)$ at atmospheric pressure (Figure 7a), the contributions of the four major pathways are as follows: 1) the $\mathrm{N}_{2} \mathrm{O}$ pathway, 2) the prompt mechanism, 3) the $\mathrm{NNH}$ pathway and 4) the thermal pathway for both mechanisms. The GDFkin ${ }^{\circledR} 3.0 \_$NOmecha2.0 mechanism predicts a higher contribution of the prompt and $\mathrm{N}_{2} \mathrm{O}$ routes compared to 
Klippenstein, while the contributions of the thermal and NNH pathways are lower for GDFkin ${ }^{\circledR} 3.0 \_$NOmecha2.0. When pressure increases, both mechanisms predict an increase of the $\mathrm{N}_{2} \mathrm{O}$ pathway contribution. For the prompt pathway, Klippenstein predicts a decrease of its contribution when pressure increases while GDFkin ${ }^{\circledR} 3.0 \_$NOmecha2.0 predicts roughly the same contribution. For the NNH pathway, both mechanisms agree with a decrease of its contribution as pressure increases. Finally, for the thermal pathway, Klippenstein predicts a slight increase and GDFkin ${ }^{\circledR}$ 3.0_NOmecha2.0 a slight decrease between 0.1 and $0.3 \mathrm{MPa}$ and the value remains almost constant between 0.5 and $0.7 \mathrm{MPa}$

In the stoichiometric flames (Figure $7 \mathrm{~b}$ ), at $0.1 \mathrm{MPa}$, the contributions of the four major pathways are as follows: 1) prompt; 2) thermal; 3) $\mathrm{NNH}$ and 4) $\mathrm{N}_{2} \mathrm{O}$ for both mechanisms. The GDFkin ${ }^{\circledR} 3.0 \_$NOmecha2.0 mechanism predicts a higher contribution of the prompt and $\mathrm{N}_{2} \mathrm{O}$ routes compared to Klippenstein, while the contributions of the thermal and NNH pathways are lower for GDFkin ${ }^{\circledR} 3.0 \_$NOmecha2.0, as for the lean flames. When pressure increases to $0.3 \mathrm{MPa}$, the contributions of the thermal and $\mathrm{N}_{2} \mathrm{O}$ pathways increase and those of the prompt and NNH pathways decrease for both mechanisms.

For the rich flames (Figure 7c), the prompt-NO pathway is clearly dominant for both mechanisms, with a small contribution of thermal and $\mathrm{NNH}$ pathways $\left(\mathrm{N}_{2} \mathrm{O}\right.$ negligible). The GDFkin ${ }^{\circledR}$ 3.0_NOmecha2.0 mechanism still predicts a higher contribution of the prompt route compared to Klippenstein, while the contributions of the thermal and NNH pathways are lower for GDFkin ${ }^{\circledR}$ 3.0_NOmecha2.0. When pressure increases, the prompt contribution increases slightly for both mechanisms and the thermal and NNH decrease slightly.

Concerning the influence of equivalence ratio, the contributions of the $\mathrm{NNH}$ and $\mathrm{N}_{2} \mathrm{O}$ pathways decrease when E.R. increases for both mechanisms. The prompt pathway becomes, as expected, more important in rich flames. Note that the thermal pathway increases from lean to stoichiometric flames but decreases for rich flames. 
The main differences observed in this analysis concerns the relative contributions of the prompt and thermal pathways between the two mechanisms, GDFkin ${ }^{\circledR} 3.0 \_$NOmecha2.0 systematically predicts a higher contribution of the prompt pathway and a lower contribution of the thermal pathway compared to Klippenstein, which can explain the differences in NO predictions between the two mechanisms, especially in rich flames.

Concerning the prompt pathway, the rate constant of the initiation reaction $\mathrm{CH}+\mathrm{N}_{2}=\mathrm{NCN}+\mathrm{H}$ is slightly higher in Klippenstein than in GDFkin ${ }^{\circledR} 3.0 \_$NOmecha2.0 around 2000K (see Table 2 and Fig.3 in [15]) but the NCN consumption reactions are also different between the two mechanisms.

Concerning the thermal route, the rate constant of the initiation reaction $\mathrm{N}_{2}+\mathrm{O}=\mathrm{NO}+\mathrm{N}$ is the one from Abian et al. [52] in Klippenstein and the one from Michael and Lim [53] in GDFkin ${ }^{\circledR}$ 3.0_NOmecha2.0, which are very close at flame temperature (see Table 2 and Fig.2 in [19]).

For the $\mathrm{NNH}$ pathways, the rate constants of the reactions $\mathrm{NNH}=\mathrm{N}_{2}+\mathrm{H}$ and $\mathrm{NNH}+\mathrm{O}=\mathrm{NH}+\mathrm{NO}$ are equivalent in both mechanisms.

Finally, for the $\mathrm{N}_{2} \mathrm{O}$ pathway, the rate constants of the pressure dependent reaction $\mathrm{N}_{2} \mathrm{O}+\mathrm{M}=\mathrm{N}_{2}+\mathrm{O}+\mathrm{M}$ and the reaction $\mathrm{NH}+\mathrm{NO}=\mathrm{N}_{2} \mathrm{O}+\mathrm{H}$ are different.

\section{b-2) Sensitivity toward NO}

To identify elementary reactions that dominate the formation of NO, sensitivity analysis was also conducted in this study (only the 20 most contributive reactions were considered). The first-order local concentration normalized sensitivity coefficients of NO were computed as a function of elementary reactions for both mechanisms. Results are presented in the supplementary files (Table C) and in Figure 8 for only the N-species containing reactions. Table $\mathrm{C}$ in the supplementary files shows that in lean conditions, sixteen common reactions appear 
sensitive in both mechanisms with close normalized sensitivity coefficients. Differences exist for the following reactions: $\mathrm{CH}_{3}+\mathrm{O} \rightarrow \mathrm{CH}_{2} \mathrm{O}+\mathrm{H} ; \mathrm{CH}_{2}+\mathrm{O}_{2} \rightarrow \mathrm{CH}_{2} \mathrm{O}+\mathrm{O} ; \mathrm{CH}_{3}+\mathrm{OH} \rightarrow \mathrm{CH}_{2}+\mathrm{H}_{2} \mathrm{O}$; $\mathrm{CH}_{2}+\mathrm{OH} \rightarrow \mathrm{CH}+\mathrm{H}_{2} \mathrm{O} ; \mathrm{CH}+\mathrm{O}_{2} \rightarrow \mathrm{HCO}+\mathrm{O} ; \mathrm{CH}_{2}+\mathrm{H} \rightarrow \mathrm{CH}+\mathrm{H}_{2} ; \mathrm{NNH} \rightarrow \mathrm{N}_{2}+\mathrm{H} ; \mathrm{N}_{2}+\mathrm{H} \rightarrow \mathrm{NNH}$. The first four appear with significant coefficients at atmospheric pressure only in the GDFkin ${ }^{\circledR}$ 3.0_NOmecha2.0 mechanism, the last four only in the Klippenstein mechanism. Under stoichiometric conditions, seventeen common reactions appear sensitive in both mechanisms with close normalized coefficients. Differences exist for the following reactions: $\mathrm{CH}_{4}+\mathrm{H} \rightarrow \mathrm{CH}_{3}+\mathrm{H}_{2} ; \quad \mathrm{CH}_{3}+\mathrm{OH} \rightarrow \mathrm{CH}_{2}+\mathrm{H}_{2} \mathrm{O} ; \quad \mathrm{CH}_{2}+\mathrm{OH} \rightarrow \mathrm{CH}+\mathrm{H}_{2} \mathrm{O} ; \quad \mathrm{CH}+\mathrm{O}_{2} \rightarrow \mathrm{HCO}+\mathrm{O} ;$ $\mathrm{NCN}+\mathrm{O} \rightarrow \mathrm{CN}+\mathrm{NO} ; \mathrm{CH}_{2}+\mathrm{H} \rightarrow \mathrm{CH}+\mathrm{H}_{2}$. The first three appear with significant coefficients at $\mathrm{P}=0.1$ and $0.3 \mathrm{MPa}$ only in the GDFkin ${ }^{\circledR} 3.0 \_$NOmecha2.0 mechanism, the last three at atmospheric pressure only in the Klippenstein mechanism. Under rich conditions, conditions for which the NO prediction deviations between the two mechanisms are greatest, only thirteen reactions are common to both mechanisms with similar coefficients. Differences exist for the following reactions: $\quad \mathrm{sCH}_{2}+\mathrm{M} \rightarrow \mathrm{CH}_{2}+\mathrm{M} ; \quad \mathrm{CH}_{2}+\mathrm{M} \rightarrow \mathrm{sCH}_{2}+\mathrm{M} ; \quad \mathrm{CH}+\mathrm{H} \rightarrow \mathrm{C}+\mathrm{H}_{2}$; $\mathrm{sCH}_{2}+\mathrm{H}_{2} \mathrm{O} \rightarrow \mathrm{CH}_{3} \mathrm{OH} ; \quad \mathrm{H}_{2} \mathrm{O}+\mathrm{O} \rightarrow 2 \mathrm{OH} ; \quad \mathrm{O}+\mathrm{H}_{2} \rightarrow \mathrm{OH}+\mathrm{H} ; \quad \mathrm{CH}_{2}+\mathrm{OH} \rightarrow \mathrm{CH}+\mathrm{H}_{2} \mathrm{O}$ $\mathrm{CH}+\mathrm{O}_{2} \rightarrow \mathrm{HCO}+\mathrm{O} ; \quad \mathrm{H}_{2} \mathrm{O}+\mathrm{H} \rightarrow \mathrm{OH}+\mathrm{H}_{2} ; \quad \mathrm{OH}+\mathrm{H}_{2} \rightarrow \mathrm{H}+\mathrm{H}_{2} \mathrm{O} ; \quad \mathrm{CH}+\mathrm{H}_{2} \mathrm{O} \rightarrow \mathrm{CH}_{2} \mathrm{O}+\mathrm{H} ;$ $\mathrm{CH}_{2} \mathrm{O}+\mathrm{H} \rightarrow \mathrm{HCO}+\mathrm{H}_{2} ; \mathrm{CH}_{2} \mathrm{O}+\mathrm{H} \rightarrow \mathrm{H}+\mathrm{CO}+\mathrm{H}_{2} ; \mathrm{NCN}+\mathrm{O} \rightarrow \mathrm{CN}+\mathrm{NO}$. The first seven appear to be significant for the GDFkin ${ }^{\circledR} 3.0 \_$NOmecha2.0 at atmospheric pressure, the last seven in the Klippenstein mechanism.

To focus on the reactions containing only N-species, Figure 8 compares the sensitivity of the $\mathrm{N}$ system reactions for the two mechanisms as a function of operating conditions. Under lean conditions, the $\mathrm{N}_{2}+\mathrm{H} \leftrightarrows \mathrm{NNH}$ reaction only appears sensitive at atmospheric pressure in the Klippenstein mechanism. The sensitivities of the other reactions are similar except for the initiation reaction of the prompt-NO formation $\mathrm{CH}+\mathrm{N}_{2} \rightarrow \mathrm{NCN}+\mathrm{H}$ which appears only at 0.1 $\mathrm{MPa}$ in the Klippenstein mechanism, the initiation reaction of the thermal-NO $\mathrm{N}_{2}+\mathrm{O} \rightarrow \mathrm{N}+\mathrm{NO}$ 
only at 0.1 and $0.3 \mathrm{MPa}$ in the GDFkin ${ }^{\circledR}$ 3.0_NOmecha2.0 mechanism and the reaction $\mathrm{N}_{2} \mathrm{O}+\mathrm{O} \rightarrow 2 \mathrm{NO}$ only at $0.1 \mathrm{MPa}$ in GDFkin ${ }^{\circledR} 3.0 \_$NOmecha2.0. For stoichiometric conditions, the $\mathrm{NCN}+\mathrm{O} \rightarrow \mathrm{CN}+\mathrm{NO}$ reaction appears only at atmospheric pressure in the Klippenstein mechanism. The other reactions occur in both mechanisms with similar sensitivity coefficients except for the $\mathrm{N}_{2} \mathrm{O}+\mathrm{H} \rightarrow \mathrm{NH}+\mathrm{NO}$ reaction, which does not occur at high pressure in the Klippenstein mechanism, and the $\mathrm{NCN}+\mathrm{H} \rightarrow \mathrm{CH}+\mathrm{N}_{2}$ reaction, which does not occur at high pressure in the GDFkin ${ }^{\circledR} 3.0 \_$NOmecha2.0 mechanism. For E.R. $=1.2$, among the four sensitive reactions, the initiation reaction of the prompt-NO appears sensitive in the direct and reverse directions in both mechanisms in the same way as a function of pressure. The $\mathrm{NCN}+\mathrm{O} \rightarrow \mathrm{CN}+\mathrm{NO}$ reaction occurs only in the Klippenstein mechanism at atmospheric pressure, and the $\mathrm{NCN}+\mathrm{H} \rightarrow \mathrm{HCN}+\mathrm{N}$ reaction only at atmospheric pressure in the Klippenstein mechanism. Comparing Figure 8 and Table 2, it can be seen that only reactions that are present in both mechanisms appear in the sensitivity analysis. No specific reaction to either mechanism appears to be important in this sensitivity analysis.

\section{Conclusion}

This work presents the validation, at high pressure, of the new NOx kinetic submechanism named NOmecha2.0, recently revised and validated in low pressure flames, jet stirred and plugflow reactors under sub-atmospheric and atmospheric pressure conditions by Lamoureux et al. [14]. NOmecha2.0 was also compared to the most recent high-pressure NOx formation mechanism available in the literature: the mechanism from Klippenstein et al. [15]. For this validation, new experimental results of NO mole fraction profile measurements were obtained by using LIF in laminar counterflow lean (E.R.=0.7), stoichiometric $($ E.R.=1.0) and rich (E.R. =1.2) $\mathrm{CH}_{4} /$ air flames stabilised at pressures ranging from 0.1 to $0.7 \mathrm{MPa}$. These results 
supplement the experimental database on NO measurements in high pressure flames available in the literature and allow discussion about the effect of pressure and equivalence ratio on NO formation. The performances of both mechanisms were also tested on NO measurements in high pressure counterflow premixed and partially premixed flames from Thomsen et al. [23,24] and Naik et al. [27]. It was shown that both mechanisms are able to predict NO mole fraction profiles in our lean and stoichiometric flames at atmospheric and high pressure. However, differences are observed in rich flames where GDFkin ${ }^{\circledR} 3.0 \_$NOmecha2.0 presents better predictions than Klippenstein. In the lean $\mathrm{CH}_{4} / \mathrm{O}_{2} / \mathrm{N}_{2}$ premixed flames from Thomsen et al. $[23,24]$ (equivalence ratio $0.7 ; \mathrm{P}=0.1-0.4 \mathrm{MPa}$ ), both mechanisms are in good agreement with experiments. However, in the partially premixed $\mathrm{CH}_{4} / \mathrm{O}_{2} / \mathrm{N}_{2}$ from Naik et al. [27] (equivalence ratio $1.45 ; \mathrm{P}=0.1-0.6 \mathrm{MPa}$ ), the agreement between experiments and modelling is less good. Kinetic analyses were then performed on both mechanisms in order to identify the main pathways that lead to the formation and consumption of NO, and highlight theirs differences. The contribution of the four major NO formation pathways (prompt, thermal, $\mathrm{NNH}$ and $\mathrm{N}_{2} \mathrm{O}$ ) was then identified for both mechanisms showing differences especially for the contribution of thermal and prompt pathways. Finally, a sensitivity analysis was presented to highlight important reactions that influence the formation and consumption of NO in our high pressure flames.

This paper demonstrates the validation of the NOmecha2.0 submechanism for NO prediction in high pressure flames. We are confident that this recently revised mechanism [14] can be associated with other hydrocarbon mechanisms, as recently shown in [54]. 


\section{$\underline{\text { Acknowledgements }}$}

This work was supported by the ANR program BLAN-08-0130(NO-Mecha) and is a contribution to the CPER research project CLIMIBIO. The authors thank the French Ministère de l'Enseignement Supérieur et de la Recherche, the Hauts de France Region, the Centre Region and the European Fund for Regional Economic Development for their financial support of this project. The authors also want to warmly thank Luc-Sy Tran for his help in using the Logesoft software. 


\section{References}

[1] Y.B. Zeldovich, The oxidation of nitrogen in combustion and explosions, Acta Physicochimica 21 (1946) 577628.

[2] C.P. Fenimore, Formation of nitric oxide in premixed hydrocarbon flames, Symp. (Int.) Combust. 13 (1971) $373-379$

[3] J.W. Bozzelli and A.M. Dean, O + NNH: A possible new route for NOx formation in flames, Int. J. Chem. Kin. 27 (1995) 1097-1109.

[4] P.C. Malte and D.T. Pratt, The role of energy-releasing kinetics in NOx formation: fuel-lean, jet-stirred COAir combustion, Combust. Sci. and Tech. 9 (1974) 221-231.

[5] L.V. Moskaleva and M.C. Lin, The Spin-Conserved Reaction $\mathrm{CH}+\mathrm{N}_{2} \rightarrow \mathrm{H}+\mathrm{NCN}$ : A Major Pathway to Prompt NO Studied by Quantum/Statistical Theory Calculations and Kinetic Modeling of Rate Constant, Proc. Combust. Inst. 28 (2000) 2393-2401.

[6] V. Vasudevan, R.K. Hanson, C.T. Bowman, D.M. Golden and D.F. Davidson, Shock tube study of the reaction of $\mathrm{CH}$ with $\mathrm{N}_{2}$ : overall rate and product branching, J. Phys. Chem. A 111 (2007) 11818-11830.

[7] A. El Bakali, L. Pillier, P. Desgroux, B. Lefort, L. Gasnot, J.F. Pauwels, I. da Costa, NO prediction in natural gas flames using GDF-Kin ${ }^{\circledR} 3.0$ mechanism: NCN and HCN contribution to prompt-NO formation, Fuel 85 (2006) 896-909.

[8] N. Lamoureux, P. Desgroux, A. El bakali and J.F. Pauwels, Experimental and numerical study of the role of $\mathrm{NCN}$ in prompt-NO formation in low pressure $\mathrm{CH}_{4}-\mathrm{O}_{2}-\mathrm{N}_{2}$ and $\mathrm{C}_{2} \mathrm{H}_{2}-\mathrm{O}_{2}-\mathrm{N}_{2}$ flames, Combust. Flame 157 (2010) 1929-1941.

[9] N. Lamoureux, X. Mercier, C. Western, J.F. Pauwels and P. Desgroux, NCN quantitative measurement in a laminar low pressure flame, Proc. Combust. Inst. 32 (2009) 937-944.

[10] N. Lamoureux, C.M. Western, X. Mercier and P. Desgroux, Reinvestigation of the spectroscopy of the $\mathrm{A}^{3} \Pi_{\mathrm{u}}-\mathrm{X}^{3} \sum_{\mathrm{g}}$ transition of the NCN radical at high temperature: application to quantitative NCN measurement in flames, Combust. Flame 160 (2013) 755-765.

[11] N. Lamoureux, H. El Merhubi, X. Mercier, J.F. Pauwels and P. Desgroux, HCN quantitative measurement in a laminar low pressure flame at 1036 nm using pulsed CRDS technique, Proc. Combust. Inst. 34 (2013) $3557-$ 3564. 
[12] N. Lamoureux, H. El Merhubi, L. Gasnot, C. Schoemaecker, P. Desgroux, Measurements and modelling of $\mathrm{HCN}$ and $\mathrm{CN}$ species profiles in laminar $\mathrm{CH}_{4} / \mathrm{O}_{2} / \mathrm{N}_{2}$ low pressure flames using LIF/CRDS techniques, Proc. Combust. Inst. 35 (2015) 745-752.

[13] N. Lamoureux, X. Mercier, J.F. Pauwels and P. Desgroux, NCO quantitative measurement in premixed low pressure flames by combining LIF and CRDS techniques, J. Phys. Chem. A 115 (2011) 5346-5353.

[14] N. Lamoureux, H. El Merhubi, L. Pillier, S. de Persis, P. Desgroux, Modeling of NO formation in low pressure premixed flames, Combust. Flame 163 (2016) 557-575.

[15] S.J. Klippensetin, M. Pfeifle, A.W. Jasper, P. Glarborg, Theory and modelling of relevance to prompt-NO formation at high pressure, Combust. Flame 195 (2018) 3-17.

[16] H. Hashemi, J.M. Christensen, S. Gersen, H.B. Levinsky, S.J. Klippenstein, P. Glarborg, High pressure oxidation of methane, Combust. Flame 172 (2016) 349-364.

[17] H. Hashemi, J.G. Jacobsen, C.T. Rasmussen, J.M. Christensen, P. Glarborg, S. Gersen, H.B. Levinsky, S.J. Klippenstein, High pressure oxidation of ethane, Combust. Flame 182 (2017) 150-166.

[18] S.J. Klippenstein, L.B. Harding, P. Glarborg, J.A. Miller, The role of NNH in NO formation and control, Combust. Flame 158 (2011) 774-789.

[19] P. Glarborg, J.A. Miller, B. Ruscic , S.J. Klippenstein, Modeling nitrogen chemistry in combustion, Prog. Energy Combust. Sci. 67 (2018) 31-68.

[20] M.S. Klassen , D.D. Thomsen , J.R. Reisel , N.M. Laurendeau , Laser-induced fluorescence measurements of nitric oxide formation in high-pressure premixed methane flames, Combust. Sci. Technol. 111 (1995) 229-247.

[21] D.D. Thomsen, F.F. Kuligowski and N.M. Laurendeau, Background corrections for laser-inducedfluorescence measurements of nitric oxide in lean, high-pressure, premixed methane flames, Applied Optics 36 (1997) 3244-3252.

[22] D.D. Thomsen, F.F. Kuligowski and N.M. Laurendeau, Modeling of NO formation in premixed, highpressure methane flames, Combust. Flame 119 (1999) 307-318.

[23] D.D. Thomsen, Measurements and modeling of nitric oxide formation in counterflow, premixed, $\mathrm{CH}_{4} / \mathrm{O}_{2} / \mathrm{N}_{2}$ flames, School of Mechanical Engineering, PhD thesis (1999), Purdue University, West Lafayette, IN, USA. http://docs.lib.purdue.edu/dissertations/AAI3017694/

[24] D.D. Thomsen and N.M. Laurendeau, LIF measurements and modeling of nitric oxide concentration in atmospheric counterflow premixed flames, Combust. Flame 124 (2001) 350-369. 
[25] R.V. Ravikrishna and N.M. Laurendeau, Laser-induced fluorescence measurements and modeling of nitric oxide in methane-air and ethane-air counterflow diffusion flames, Combust. Flame 120 (2000) 372-382.

[26] R.V. Ravikrishna and N.M. Laurendeau, Laser-induced fluorescence measurements and modeling of nitric oxide in counterflow partially premixed flames, Combust. Flame 122 (2000) 474-482.

[27] S.V. Naïk and N.M. Laurendeau, LIF measurements and chemical kinetics analysis of nitric oxide formation in high-pressure counterflow partially premixed and nonpremixed flames, Combust. Sci. and Tech. 176 (2004) 1809-1853.

[28] S.V. Naïk and N.M. Laurendeau, Spectroscopic, calibration and RET issues for linear laser-induced fluorescence measurements of NO in high-pressure diffusion flames, Appl. Phys. B 79 (2004) 641-651.

[29] R.V. Ravikrishna, S.V. Naïk, C.S. Cooper and N.M. Laurendeau, Quantitative laser-induced fluorescence measurements and modeling of nitric oxide in high-pressure (6-15 atm) counterflow diffusion flames, Combust. Sci. and Tech. 176 (2004) 1-21.

[30] S.V. Naïk and N.M. Laurendeau, Effects of CH-NO interactions on kinetics of prompt NO in high-pressure counterflow flames, Energy and Fuels 22 (2008) 250-261.

[31] M.D. Di Rosa, K.G. Klavuhn and R.K. Hanson, LIF spectroscopy of $\mathrm{NO}$ and $\mathrm{O}_{2}$ in high-pressure flames, Combust. Sci. and Tech.. 118 (1996) 257-283.

[32] W.G. Bessler, C. Schulz, T. Lee, J.B. Jeffries and R.K. Hanson, Strategies for laser-induced-fluorescence of nitric oxide in high-pressure flames. I. A-X(0,0) excitation, Applied Optics 41 (2002) 3547-3557.

[33] W.G. Bessler, C. Schulz, T. Lee, D.I. Shin, M. Hofmann, J.B. Jeffries, J. Wolfrum and R.K. Hanson, Quantitative NO-LIF imaging in high pressure flames, Applied Physics B 75 (2002) 97-102.

[34] W.G. Bessler, C. Schulz, T. Lee, J.B. Jeffries and R.K. Hanson, Strategies for laser-induced fluorescence detection of nitric oxide in high-pressure flames. II. A-X(0,1) excitation, Applied Optics 42 (2003) 2031-2042.

[35] W.G. Bessler, C. Schulz, T. Lee, J.B. Jeffries and R.K. Hanson, Strategies for laser-induced fluorescence detection of nitric oxide in high-pressure flames. III. Comparison of A-X excitation schemes, Applied Optics 42 (2003) 4922-4936.

[36] G.M.G Watson, P. Versailles, J.M. Bergthorson, NO formation in premixed flames of $\mathrm{C}_{1}-\mathrm{C}_{3}$ alkanes and alcohols, Combust. Flame 169 (2016) 242-260.

[37] P. Versailles, G.M.G. Watson, A.C.A. Lipardi, J.M. Bergthorson, Quantitative CH measurements in atmospheric-pressure, premixed flames of C1-C4 alkanes, Combust. Flame 165 (2016) 109-124. 
[38] P. Versailles, G.M.G. Watson, A. Durocher, G. Bourque, J.M. Bergthorson, Thermochemical mechanism optimization for accurate predictions of $\mathrm{CH}$ concentrations in premixed flames of C1-C3 alkane fuels, J. Eng. Gas Turbines Power 140 (6), 061508 (14 pages).

[39] P. Versailles, A. Durocher, G. Bourque, J.M. Bergthorson, Nitric oxide formation in lean, methane-air stagnation flames at supra-atmospheric pressures, Proc. Combust. Inst. 37 (2019) 711-718.

[40] C.W. Zhou, Y. Li, E. O'Connor, et al., A comprehensive experimental and modeling study of isobutene oxidation, Combust. Flame 167 (2016) 353-379.

[41] M.D. Bohon, T.F. Guiberti, S.M. Sarathy, W.L. Roberts, Variations in non-thermal NO formation pathways in alcohol flames, Proc. Combust. Inst. 36 (2017) 3995-4002.

[42] M.D. Bohon, T.F. Guiberti, W.L. Roberts, PLIF measurements of non-thermal NO concentrations in alcohol and alkane flames, Combust. Flame 194 (2018) 363-375.

[43] Y. Zhou, Z. Wang, Y. He, R. Whiddon, D. Xu, Z. Li, K. Cen, Effects of CH4 content on NO formation in one-dimensional adiabatic flames investigated by saturated laser-induced fluorescence and CHEMKIN modelling, Energy Fuels 31 (2017) 3154-3163.

[44] L. Pillier, M. Idir, J. Molet, A. Matynia, S. de Persis, Experimental study and modelling of NOx formation in high pressure counter-flow premixed $\mathrm{CH}_{4}$ /air flames, Fuel 150 (2015) 394-407.

[45] LOGERESEARCH, http://logesoft.com/loge-software/, LOGE AB, 2017

[46] A. El Bakali, P. Dagaut, L. Pillier , P. Desgroux , J-F. Pauwels , A. Rida and P. Meunier, Experimental and modeling study of the oxidation of natural gas in a premixed flame, shock tube, and jet-stirred reactor, Combust. Flame 137 (2004) 109-128.

[47] A. Matynia, M. Idir, J. Molet, C. Roche, S. de Persis and L. Pillier, Absolute OH concentration profiles measurements in high pressure counterflow flames by coupling LIF, PLIF and absorption techniques, Appl. Phys. B 108 (2012) 393-405.

[48] A. Matynia, J. Molet, C. Roche, M. Idir, S. de Persis and L. Pillier, Measurement of OH concentration profiles by laser diagnostics and modelling in high pressure counter-flow premixed methane-air and biogas-air flames, Combust. Flame 159 (2012) 3300-3311.

[49] J.P. Gore, J. Lim, T. Takeno, X.L. Zhu, A Study of the Effects of Thermal Radiation on the structure of Methane/Air Counter-Flow Diffusion Flames Using Detailed Chemical Kinetics,,Proceedings of the 5th ASME/JSME Joint Thermal Engineering Conference, San Diego, California, 1999. 
[50] S. Bhattacharjee, W.L. Grosshandler, Effect of radiative heat transfer on combustion chamber flows, Combust. Flame 77 (1989) 347-357.

[51] L. Pillier, A. El Bakali, X. Mercier, A. Rida, J.F. Pauwels, P. Desgroux, Influence of $\mathrm{C}_{2}$ and $\mathrm{C}_{3}$ compounds of natural gas on NO formation: an experimental study based on LIF/CRDS coupling, Proc. Combust. Inst.30 (2005) 1183-1191.

[52] M. Abian, M.U. Alzueta, P. Glarborg, Formation of NO from N2/O2 mixtures in a flow reactor: towards an accurate prediction of thermal NO, Int. J. Chem. Kinet. 47 (2015) 518-32.

[53] J.V. Michael, K.P. Lim, Rate constants for the N2O reaction system -thermal-decomposition of N2O, $\mathrm{N}+\mathrm{NO}=\mathrm{N} 2+\mathrm{O}$ and implications for $\mathrm{O}+\mathrm{N} 2=\mathrm{NO}+\mathrm{N}, \mathrm{J}$. Chem. Phys. 97 (1992) 3228-34.

[54] M.D Sylla, N. Lamoureux, L. Gasnot, Impact of methyl butanoate oxidation on NO formation in laminar low pressure flames, Fuel 207 (2017) 801-813. 


\section{$\underline{\text { List of table captions }}$}

Table 1. $\mathrm{CH}_{4} /$ air counterflow premixed flame conditions $\left(\mathrm{X}\left(\mathrm{CH}_{4}\right)\right.$ is the mole fraction of methane, $\mathrm{X}\left(\mathrm{O}_{2}\right)$ is the mole fraction of oxygen and $\mathrm{X}\left(\mathrm{N}_{2}\right)$ is the mole fraction of nitrogen); Air dilution ratio is used.

Table 2. Rate constants calculated at 2000K for the reactions involved in the prompt-NO sub-mechanism and NCN chemistry, the thermal-NO initiation, the $\mathrm{NNH}$ pathway and the $\mathrm{N}_{2} \mathrm{O}$ pathway for the GDFkin ${ }^{\circledR}$ 3.0_NOmecha2.0 and Klippenstein mechanisms. 


\section{$\underline{\text { List of tables }}$}

\section{$\underline{\text { Table } 1 .}$.}

\begin{tabular}{|c|c|c|c|c|c|c|c|c|c|}
\hline 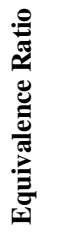 & 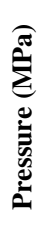 & $\mathbf{X}\left(\mathbf{C H}_{4}\right)$ & $\mathbf{X}\left(\mathbf{O}_{2}\right)$ & $\mathbf{X}\left(\mathbf{N}_{2}\right)$ & $\begin{array}{c}\text { Total flowrate } \\
\left.(\text { L.min })^{-1}\right)^{\mathbf{a}}\end{array}$ & $\begin{array}{c}\text { Inlet premixed } \\
\text { gas } \\
\text { Velocity } \\
\left.\left(\mathrm{cm}^{-1}\right)^{\mathrm{a}}\right)^{\mathrm{a}}\end{array}$ & $\boldsymbol{\beta}^{\mathbf{b}}$ & $\begin{array}{l}\text { Burner cooled } \\
\text { temperature }(K)\end{array}$ & $\begin{array}{c}\text { Adiabatic } \\
\text { flame } \\
\text { temperature } \\
(\mathbf{K})^{c}\end{array}$ \\
\hline \multirow{4}{*}{0.7} & 0.1 & \multirow{4}{*}{0.0685} & \multirow{4}{*}{0.1952} & \multirow{4}{*}{0.7363} & 1.57 & 75.3 & 1.05 & 303 & 1841 \\
\hline & 0.3 & & & & 2.50 & 42.0 & 1.05 & 313 & 1849 \\
\hline & 0.5 & & & & 2.97 & 30.9 & 1.05 & 323 & 1857 \\
\hline & 0.7 & & & & 4.01 & 29.7 & 1.05 & 323 & 1857 \\
\hline \multirow[t]{2}{*}{1} & 0.1 & \multirow[t]{2}{*}{0.0947} & \multirow[t]{2}{*}{0.1896} & \multirow[t]{2}{*}{0.7157} & 2.75 & 132.1 & 1 & 303 & 2223 \\
\hline & 0.3 & & & & 7.56 & 126.8 & 1 & 313 & 2251 \\
\hline \multirow{3}{*}{1.2} & 0.1 & \multirow{3}{*}{0.1010} & \multirow{3}{*}{0.1835} & \multirow{3}{*}{0.7065} & 2.21 & 106.1 & 1.05 & 303 & 2190 \\
\hline & 0.3 & & & & 6.07 & 101.8 & 1.05 & 313 & 2205 \\
\hline & 0.5 & & & & 7.35 & 76.4 & 1.05 & 323 & 2215 \\
\hline
\end{tabular}

${ }^{a}$ Experimental conditions for the bottom burner, in standard conditions, i.e. $T=273 \mathrm{~K}$ and $\mathrm{P}=101325 \mathrm{~Pa}$.

${ }^{b} \beta=$ inlet premixed gas velocity (top burner) / inlet premixed gas velocity (bottom burner)

${ }^{c}$ Flame temperature calculated for a free flame configuration using GDFkin ${ }^{\circledR} 3.0$ associated with NOMecha2.0 


\section{Table 2.}

\begin{tabular}{|c|c|c|}
\hline \multirow{2}{*}{$\begin{array}{c}\text { Reactions } \\
\text { First order: } \mathrm{s}^{-1} \\
\text { Second order: } \mathrm{cm}^{3} / \mathrm{mol}^{2} \cdot \mathrm{s} \\
\text { Third order: } \mathrm{cm}^{6} / \mathrm{mol}^{2} \cdot \mathrm{s} \\
R=1.987 \mathrm{cal} / \mathrm{mol}^{\prime} \cdot \mathrm{K}\end{array}$} & \multicolumn{2}{|c|}{ Rate constant@2000K } \\
\hline & GDFkin $^{\circledR} 3.0 \_N O m e c h a 2.0$ & Klippenstein \\
\hline \multicolumn{3}{|c|}{ Prompt-NO initiation and NCN consumption } \\
\hline $\mathrm{CH}+\mathrm{N}_{2} \rightleftharpoons \mathrm{NCN}+\mathrm{H}$ & $2.76 \times 10^{10}$ & $3.31 \times 10^{10}$ \\
\hline $\mathrm{NCN}+\mathrm{H} \rightleftharpoons \mathrm{HCN}+\mathrm{N}$ & $5.19 \times 10^{13}$ & $1.27 \times 10^{13}$ \\
\hline $\mathrm{NCN}+\mathrm{H} \rightleftharpoons \mathrm{HNCN}$ & $1.14 \times 10^{10}$ & $5.88 \times 10^{11}$ \\
\hline $\mathrm{NCN}+\mathrm{O}_{2} \rightleftharpoons \mathrm{NO}+\mathrm{NCO}$ & $3.74 \times 10^{8}$ & $3.82 \times 10^{9}$ \\
\hline $\mathrm{NCN}+\mathrm{OH} \rightleftharpoons \mathrm{HCN}+\mathrm{NO}$ & $4.87 \times 10^{11}$ & $1.12 \times 10^{12}$ \\
\hline $\mathrm{NCN}+\mathrm{O} \rightleftharpoons \mathrm{CN}+\mathrm{NO}$ & $6.77 \times 10^{13}$ & $9.18 \times 10^{13}$ \\
\hline $\mathrm{NCN}+\mathrm{H}_{2} \rightleftharpoons \mathrm{HNCN}+\mathrm{H}$ & $9.41 \times 10^{10}$ & - \\
\hline $\mathrm{NCN}+\mathrm{M} \rightleftharpoons \mathrm{C}+\mathrm{N}_{2}+\mathrm{M}$ & $1.45 \times 10^{8}$ & $1.46 \times 10^{8}$ \\
\hline $\mathrm{NCN}+\mathrm{NCN} \rightleftharpoons 2 \mathrm{CN}+\mathrm{N}_{2}$ & $3.70 \times 10^{12}$ & _- \\
\hline $\mathrm{NCN}+\mathrm{C} \rightleftharpoons 2 \mathrm{CN}$ & $1.00 \times 10^{14}$ & _- \\
\hline $\mathrm{NCN}+\mathrm{N} \rightleftharpoons \mathrm{CN}+\mathrm{N}_{2}$ & $1.00 \times 10^{13}$ & - \\
\hline $\mathrm{NCN}+\mathrm{CN} \rightleftharpoons \mathrm{C}_{2} \mathrm{~N}_{2}+\mathrm{N}$ & $1.67 \times 10^{13}$ & - \\
\hline $\mathrm{NCN}+\mathrm{H} \rightleftharpoons \mathrm{HNC}+\mathrm{N}$ & _- & $7.07 \times 10^{11}$ \\
\hline $\mathrm{NCN}+\mathrm{OH} \rightleftharpoons \mathrm{NCNOH}$ & - & $6.29 \times 10^{10}$ \\
\hline $\mathrm{NCN}+\mathrm{OH} \rightleftharpoons \mathrm{NCO}+\mathrm{NH}$ & - & $5.46 \times 10^{11}$ \\
\hline $\mathrm{NCN}+\mathrm{NO} \rightleftharpoons \mathrm{CN}+\mathrm{N}_{2} \mathrm{O}$ & _ & $3.91 \times 10^{11}$ \\
\hline \multicolumn{3}{|c|}{ Thermal-NO initiation } \\
\hline $\mathrm{N}_{2}+\mathrm{O} \rightleftharpoons \mathrm{N}+\mathrm{NO}$ & $5.63 \times 10^{5}$ & $6.58 \times 10^{5}$ \\
\hline $\mathrm{N}+\mathrm{O}_{2} \rightleftharpoons \mathrm{NO}+\mathrm{O}$ & $2.63 \times 10^{12}$ & idem \\
\hline $\mathrm{N}+\mathrm{OH} \rightleftharpoons \mathrm{NO}+\mathrm{H}$ & $3.80 \times 10^{13}$ & idem \\
\hline \multicolumn{3}{|c|}{ NNH pathway } \\
\hline $\mathrm{NNH} \rightleftharpoons \mathrm{N}_{2}+\mathrm{H}$ & $1.00 \times 10^{9}$ & idem \\
\hline $\mathrm{NNH}+\mathrm{O} \rightleftharpoons \mathrm{NH}+\mathrm{NO}$ & $1.03 \times 10^{13}$ & idem \\
\hline \multicolumn{3}{|c|}{$\mathrm{N}_{2} \mathrm{O}$ pathway } \\
\hline $\mathrm{N}_{2} \mathrm{O}+\mathrm{M} \rightleftharpoons \mathrm{N}_{2}+\mathrm{O}+\mathrm{M}$ & $\begin{array}{c}\text { HIGH PRESSURE1.89 x } 10^{5} \\
\text { LOW PRESSURE } 2.61 \times 10^{8} \\
\mathrm{~N}_{2} / 1.7 / \mathrm{O}_{2} / 1.4 / \mathrm{CO}_{2} / 3.0 / \mathrm{H}_{2} \mathrm{O} / 12.0 /\end{array}$ & $\begin{array}{c}\text { HIGH PRESSURE4.66 x } 10^{4} \\
\text { LOW PRESSURE } 3.17 \times 10^{8} \\
\mathrm{~N}_{2} / 1.7 / \mathrm{O}_{2} / 1.4 / \mathrm{H}_{2} \mathrm{O} / 12.0 /\end{array}$ \\
\hline $\mathrm{NH}+\mathrm{NO} \rightleftharpoons \mathrm{N}_{2} \mathrm{O}+\mathrm{H}$ & $1.29 \times 10^{13}$ & $7.15 \times 10^{12}$ \\
\hline $\mathrm{N}_{2} \mathrm{O}+\mathrm{O} \rightleftharpoons 2 \mathrm{NO}$ & $8.69 \times 10^{10}$ & idem \\
\hline
\end{tabular}




\section{List of figure captions}

Figure 1: Pictures of the $\mathrm{CH}_{4} /$ air flames stabilised in this work: a) for E.R.=0.7 at pressures from $P=0.1$ to 0.7 $M P a ; b)$ for $E . R .=1.0$ at pressures from $P=0.1$ to $0.3 \mathrm{MPa}$; ) for $E . R .=1.2$ at pressures from $P=0.1$ to 0.5 $M P a$.

Figure 2: Laminar flame velocities of $\mathrm{CH}_{4} /$ air mixture at 0.1 and $0.5 \mathrm{MPa}$ (initial temperature $=300 \mathrm{~K}$ ) calculated using GDFkin ${ }^{\circledR} 3.0 \_N O m e c h a 2.0$ mechanism (red line) and Klippenstein mechanism (blue dashed line), compared to experimental results from Vagelopoulos et al. (1994), Dong et al. (2002), Gu et al. (2000), Rozenchan et al. (2002), Halter et al. (2005) and Goswami et al. (2013).

Figure 3: Experimental $\mathrm{NO}$ mole fraction profiles (in ppm) for all the $\mathrm{CH}_{4} /$ air counterflow flames conditions: a) for E.R. $=0.7$ at pressures from $P=0.1$ to $0.7 \mathrm{MPa} ; b)$ for $E . R .=1.0$ at pressures from $P=0.1$ to $0.3 \mathrm{MPa}$; ) for E.R. $=1.2$ at pressures from $P=0.1$ to $0.5 \mathrm{MPa}$.

Figure 4: Comparison between experimental and calculated $\mathrm{NO}$ mole fraction profiles for $\mathrm{CH}_{4} / a i r$ flames: a) for E.R. $=0.7$ at pressures from $P=0.1$ to $0.7 \mathrm{MPa}$; $b$ ) for $E . R .=1.0$ at pressures from $P=0.1$ to $0.3 \mathrm{MPa}$; ) for E.R. $=1.2$ at pressures from $P=0.1$ to $0.5 \mathrm{MPa}$.

Symbols: experiments; modeling with red solid line: GDFkin ${ }^{\circledR} 3.0$ with NOmecha2.0, blue dotted line: Klippenstein mechanism.

Figure 5: Comparison between experimental and calculated peak NO mole fraction for CHAlair flames for E.R. $=0.7$ at pressures from $P=0.1$ to $0.4 \mathrm{MPa}$.

Circle symbols: experiments obtained by Thomsen et al. [23,24]; modeling with red solid line: GDFkin ${ }^{\circledR} 3.0$ with NOmecha2.0, modeling with blue dotted line: Klippenstein mechanism.

Figure 6: Comparison between experimental and calculated NO mole fraction profiles for partially premixed $\mathrm{CH}_{4}$ /air flames for E.R.=1.45 obtained by Naik et al. [27]: at a) $P=0.1 M P a$; b) $P=0.3 M P a$ and c) $P=0.6 M P a$. Crosses symbols: experiments obtained by Naik et al. [27]; modeling with red solid line: GDFkin ${ }^{\circledR} 3.0$ with NOmecha2.0, modeling with blue dotted line: Klippenstein mechanism. 
Figure 7: Relative contribution (in \%) of the four $\mathrm{NO}$ formation pathways (prompt, thermal, $\mathrm{NNH}$ and $\mathrm{N}_{2} \mathrm{O}$ routes) obtained from $N_{2}$ consumption rates: a) for E.R. $=0.7$; b) for E.R.=1.0 and c) for E.R.=1.2, as a function of pressure in premixed $\mathrm{CH}_{4} /$ air counterflow flames with GDFkin ${ }^{\circledR} 3.0 \_$NOmecha2.0 in red and with Klippenstein mechanism in blue.

Figure 8: Normalized sensitivity coefficients of NO to reaction rate coefficients (only $N$-species containing reactions are considered): a) for E.R.=0.7, b) for E.R.=1, c) for E.R.=1.2, as a function of pressure $(0.1 \mathrm{MPa}$ in black, 0.3MPa in red, 0.5MPa in blue, 0.7MPa in green), for GDFkin®3.0 associated with NOmecha2.0 (left column) and Klippenstein mechanism (right column). 
Figure 1

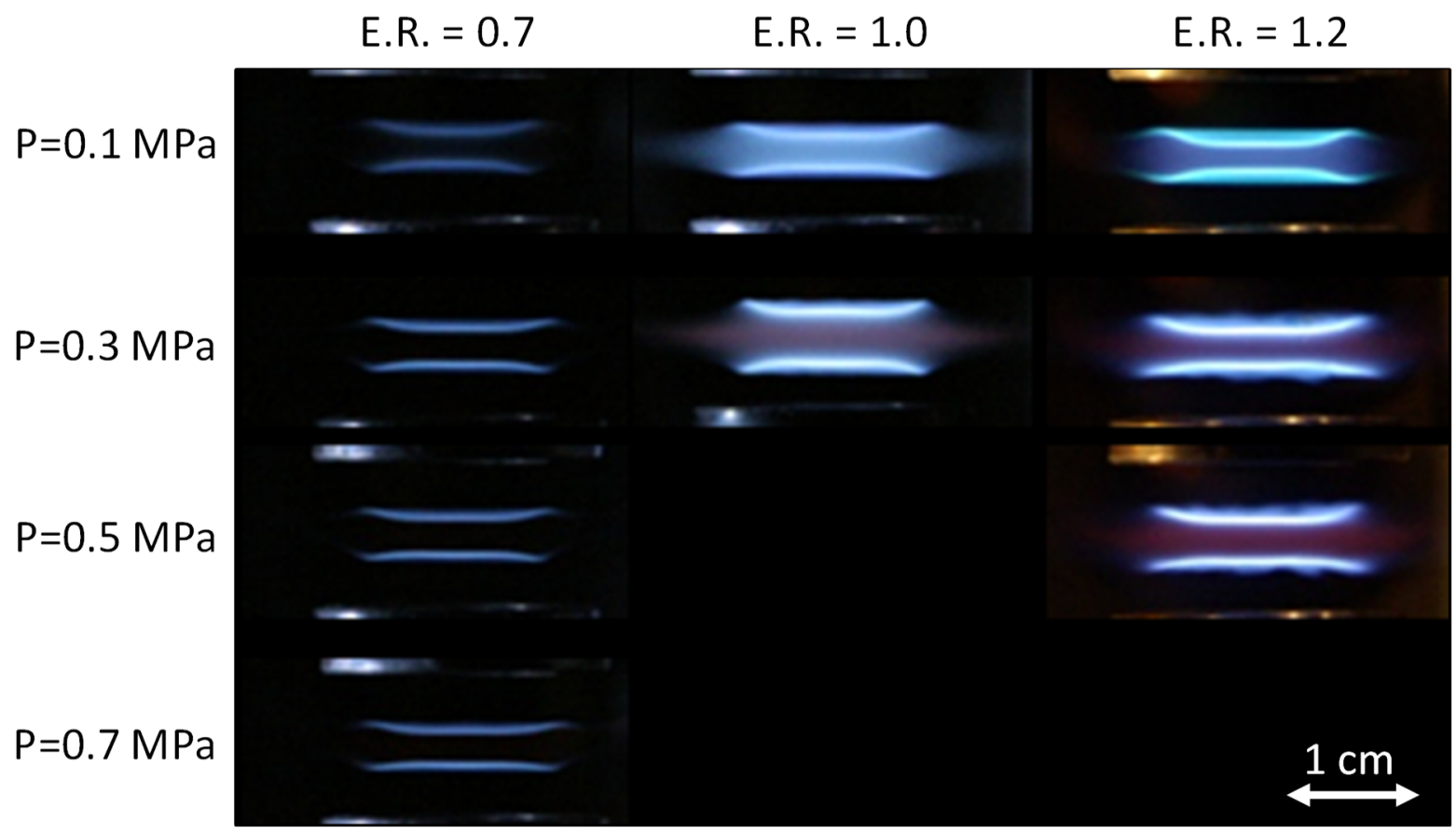


Figure 2

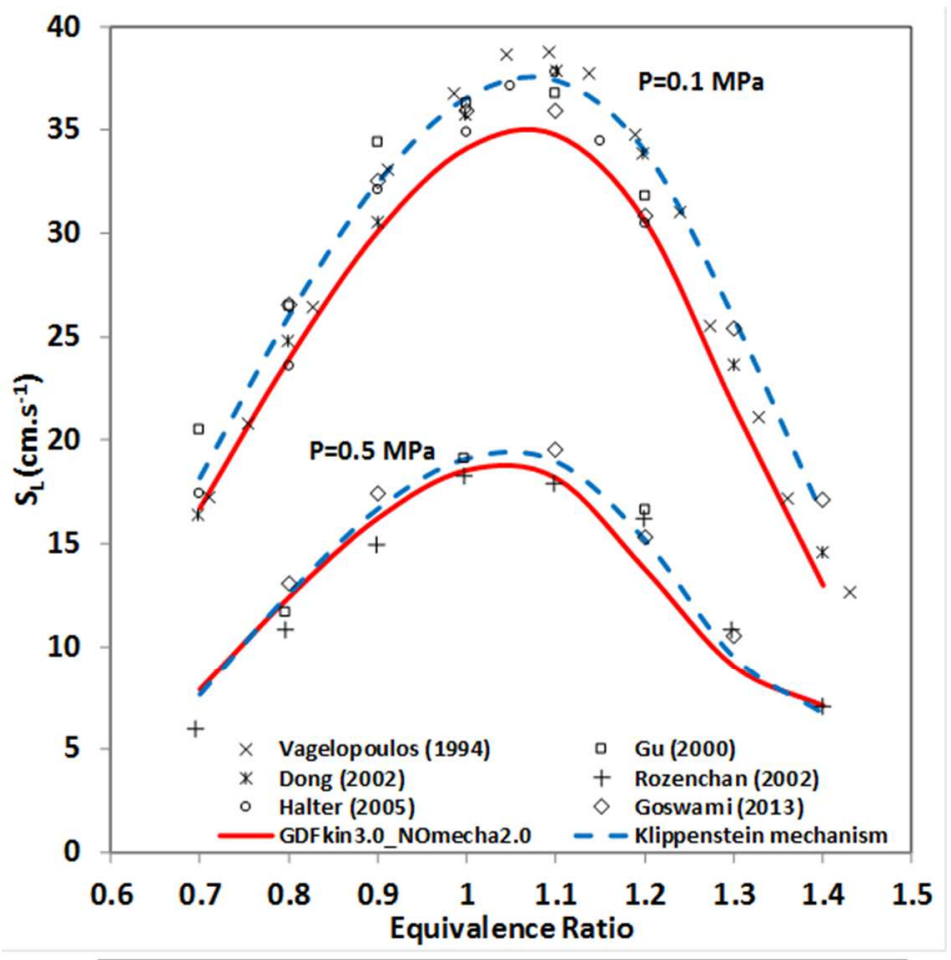

References:

Dong et al., Proc. Combust. Inst. 29 (2002) 1419-1426; Goswami et al. Combust. Flame 160 (9) (2013) 1627-1635; Gu et al., Combust. Flame 121 (1-2) (2000) 41-58;

Halter et al., Proc. Combust. Inst. 30 (2005) 201-208; Rozenchan et al., Proc. Combust. Inst. 29 (2) (2002) 14611470;

Vagelopoulos and Egolfopoulos., Proc. Combust. Inst. 25 (1994) 1317-1323. 
Figure 3

a)

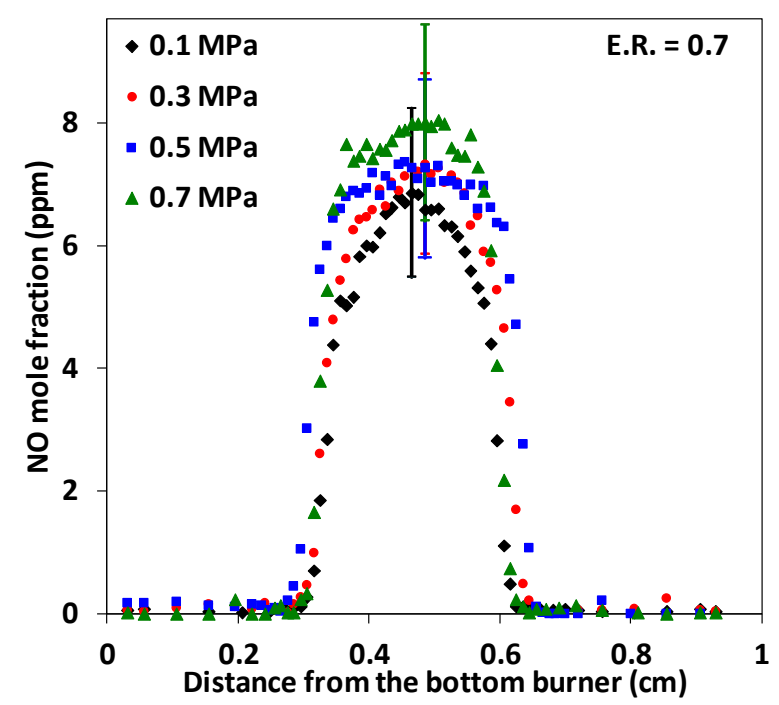

c)

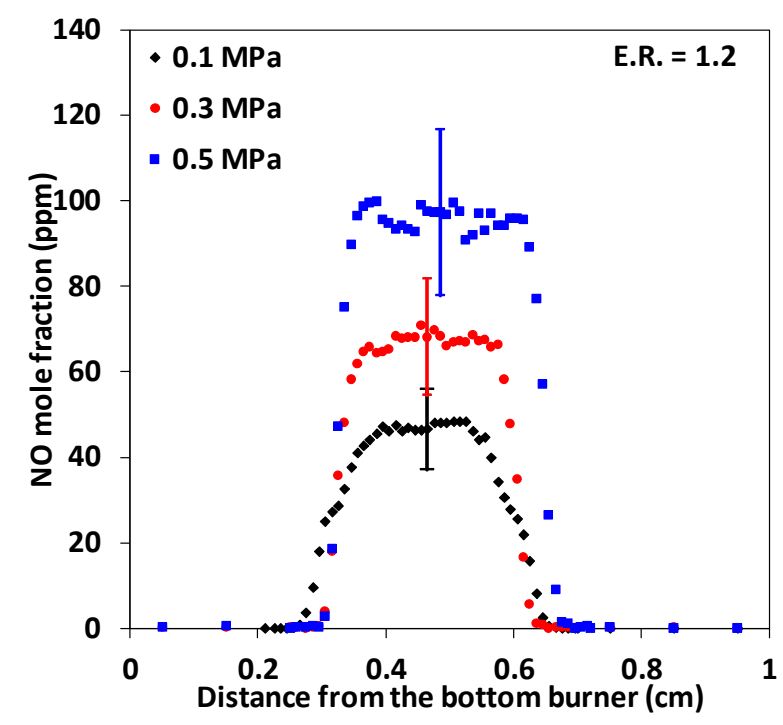

b)

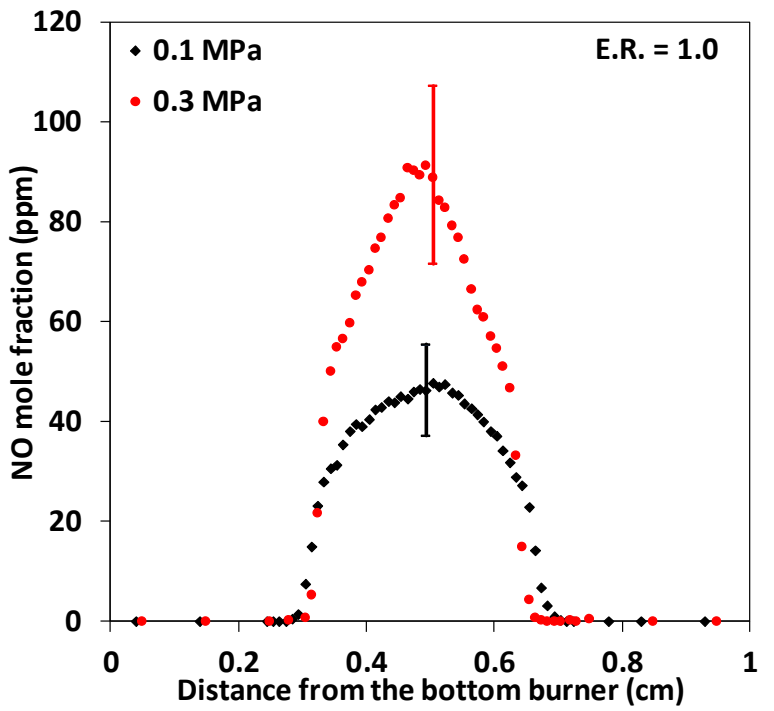


Figure 4

a)
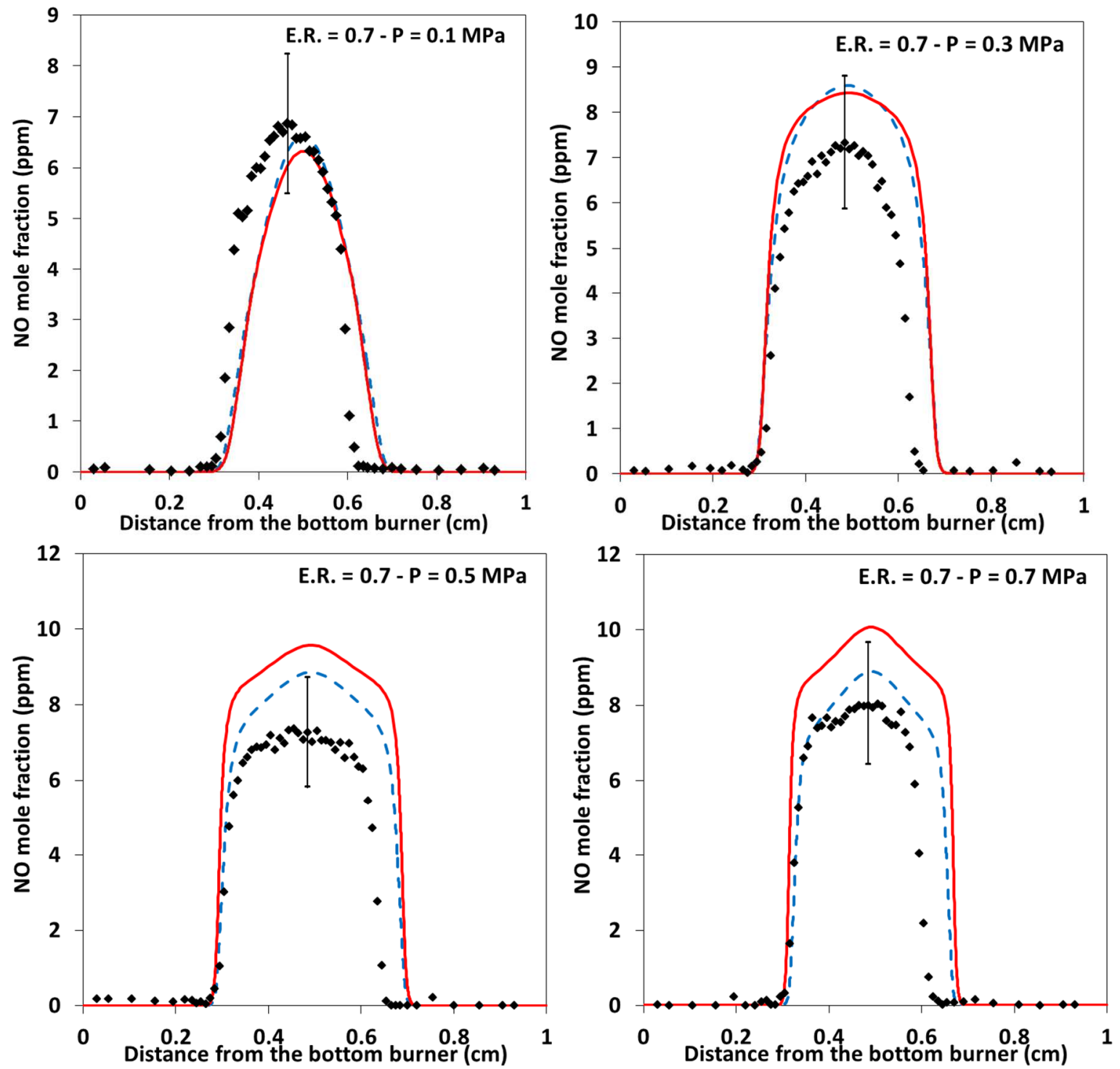

b)
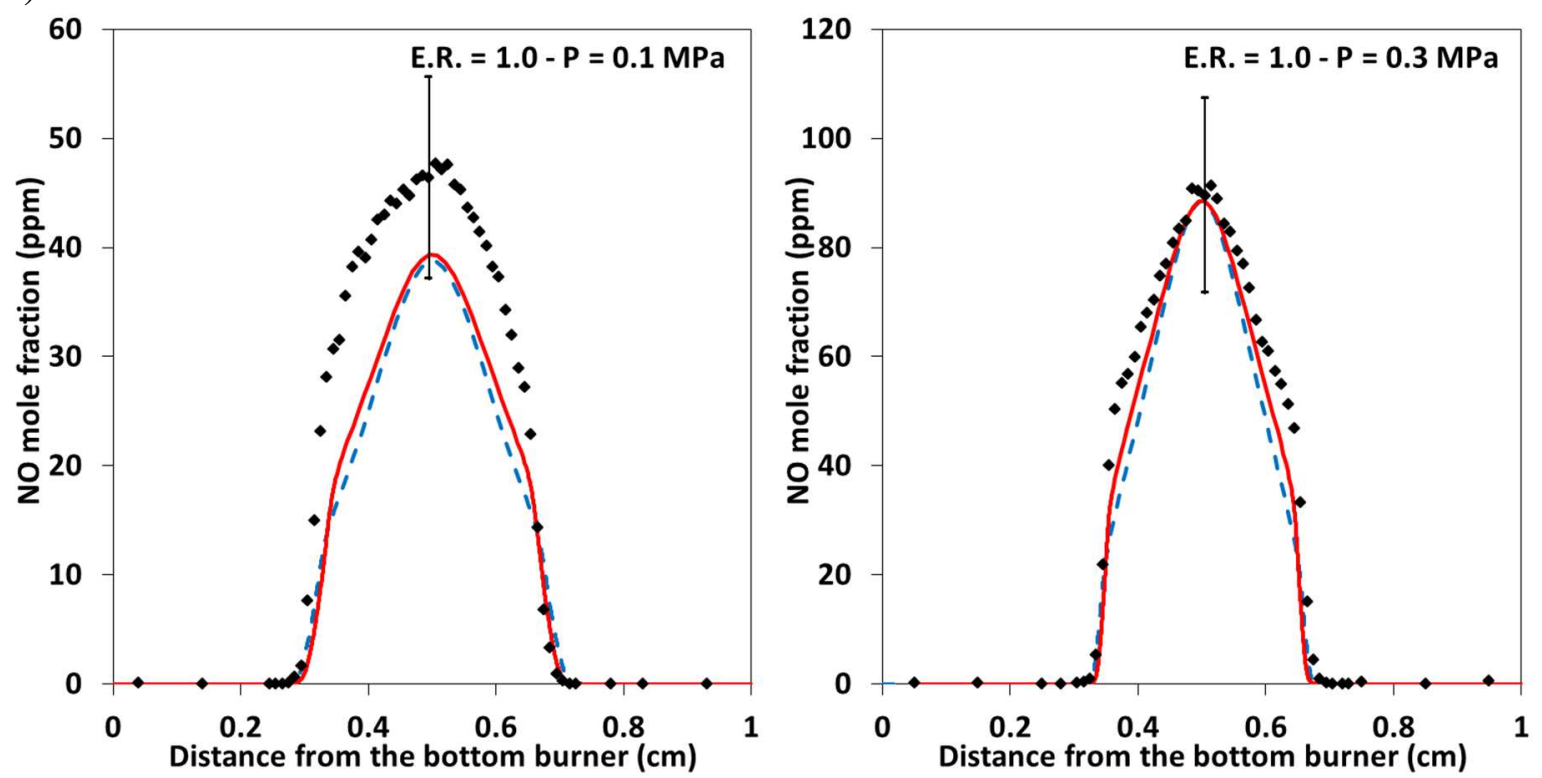
c)
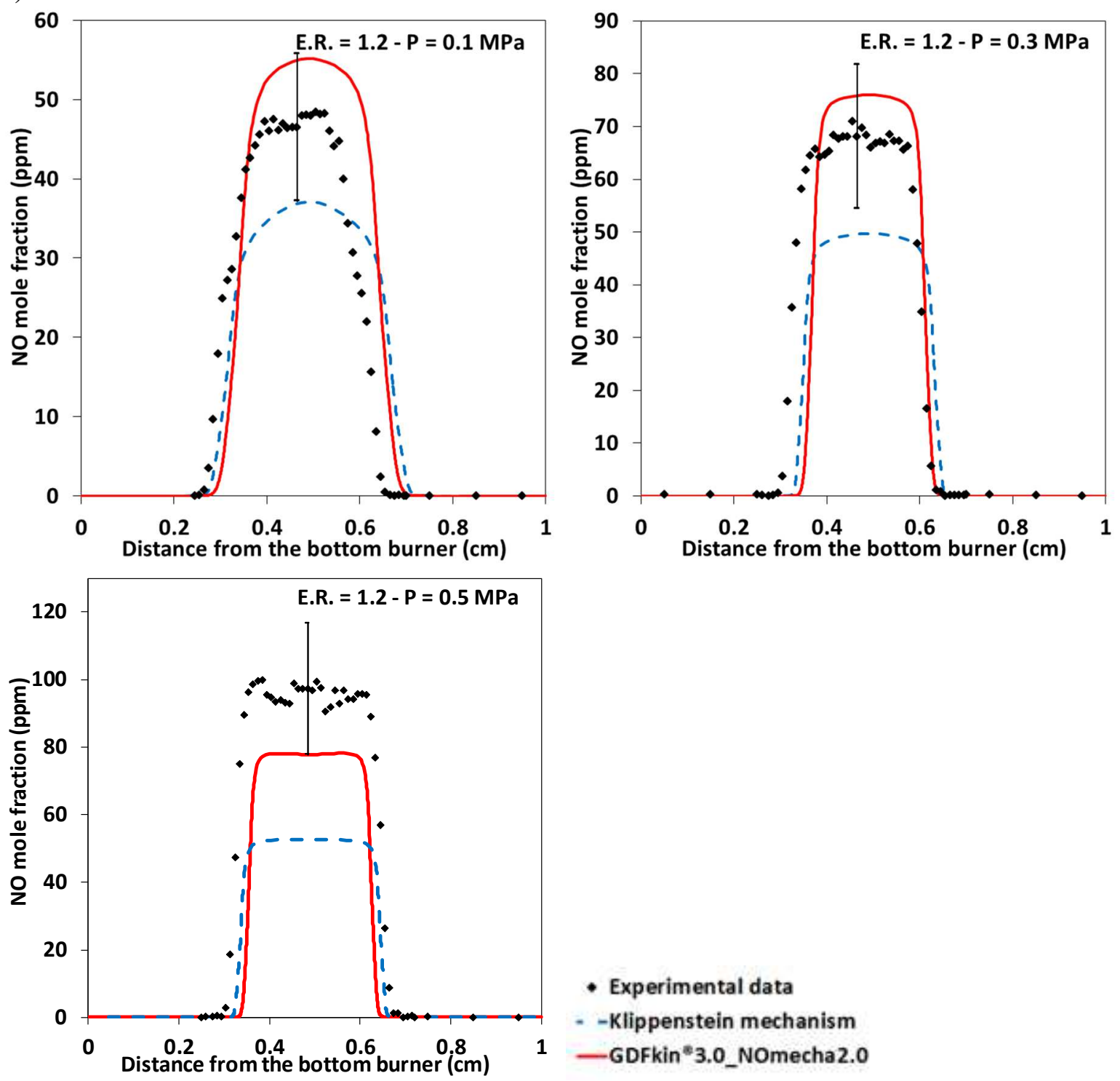
Figure 5

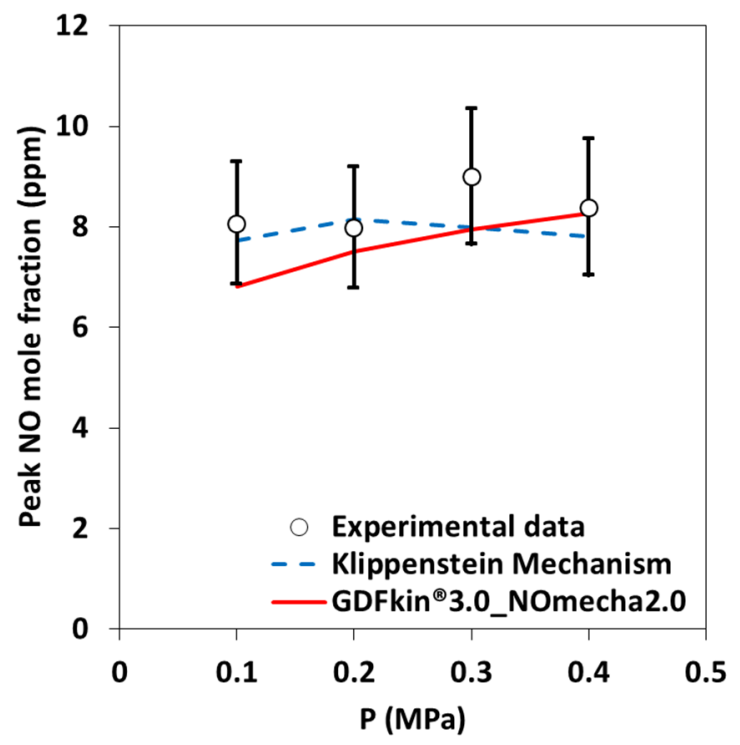


Figure 6

a)

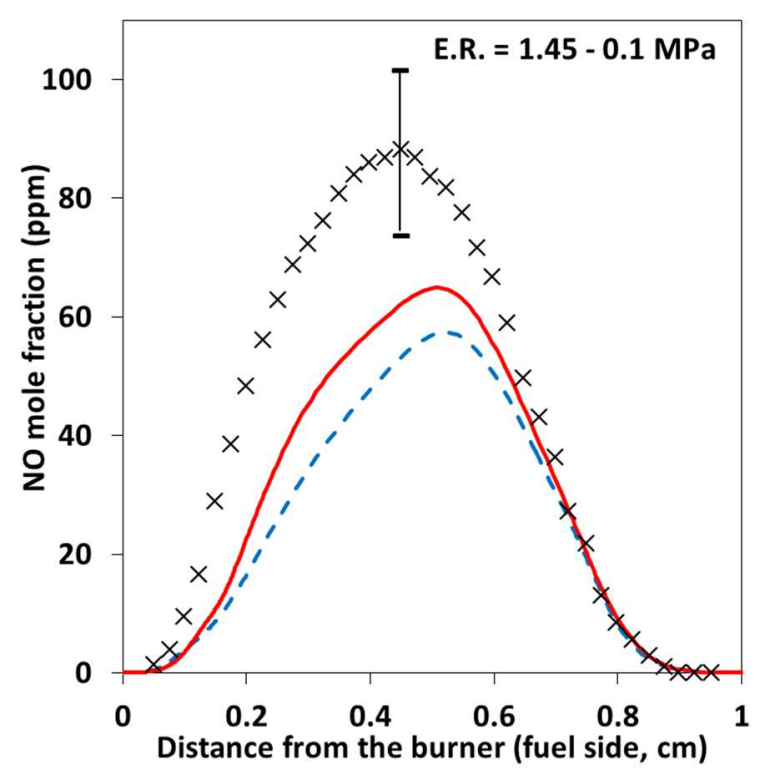

c)

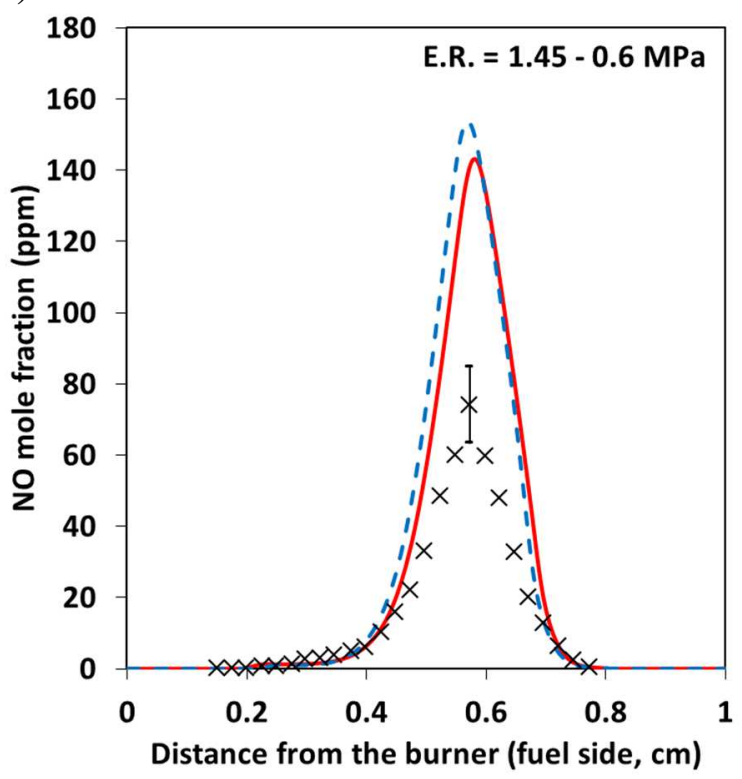

$\times$ Experimental data

- - Klippenstein Mechanism

- GDFkin ${ }^{\circledR}$ 3.0_NOmecha2.0 b)

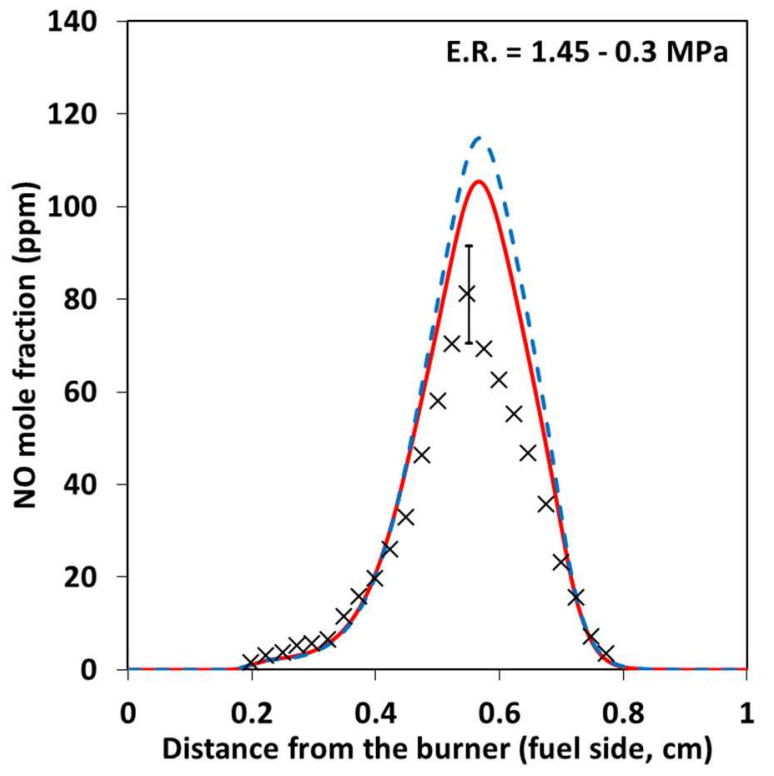


Figure 7

a)
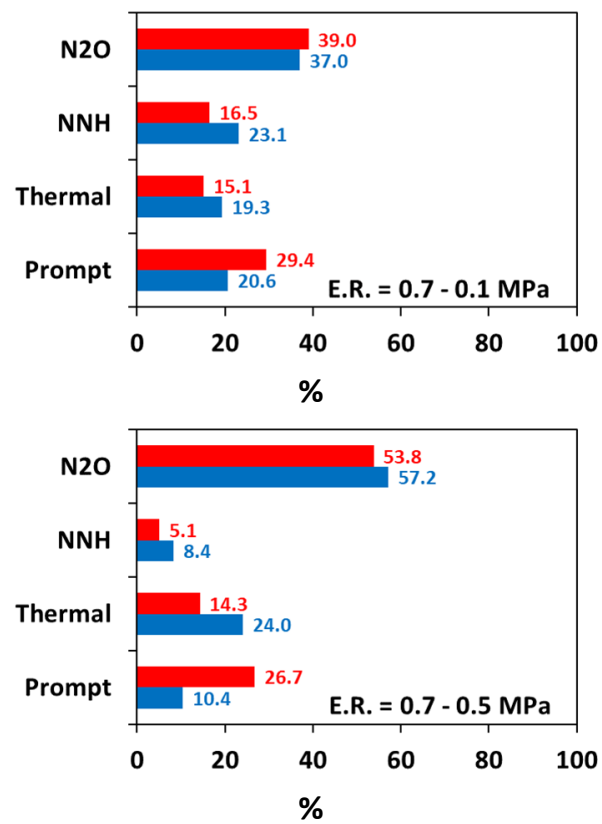

b)

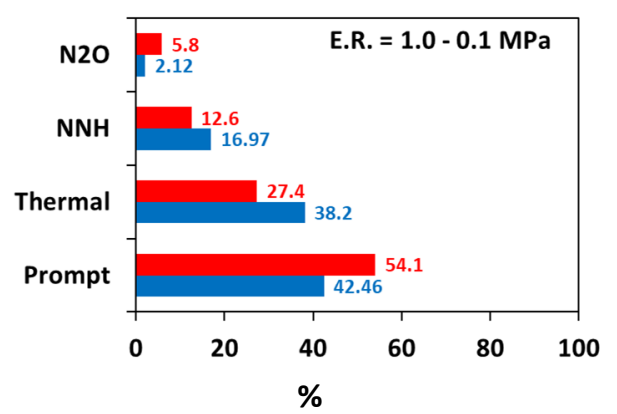

c)
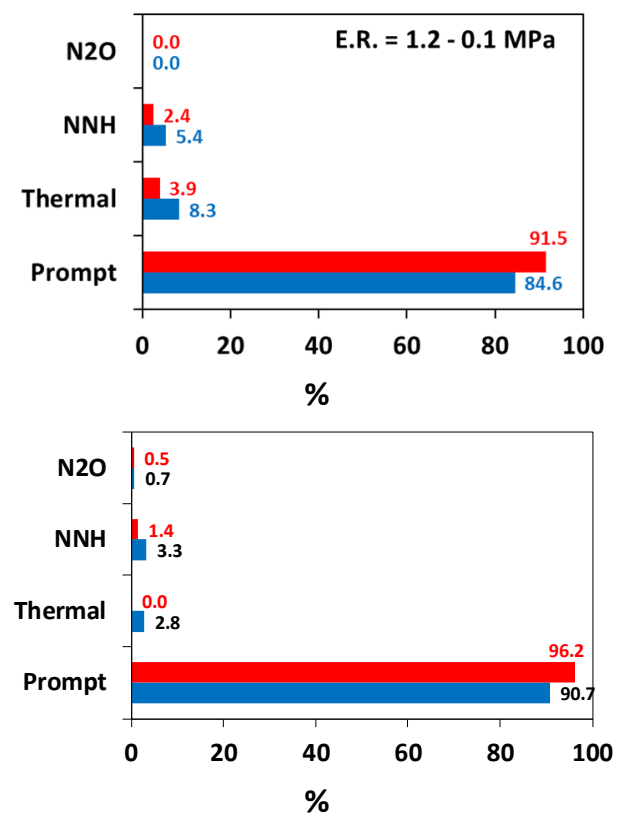
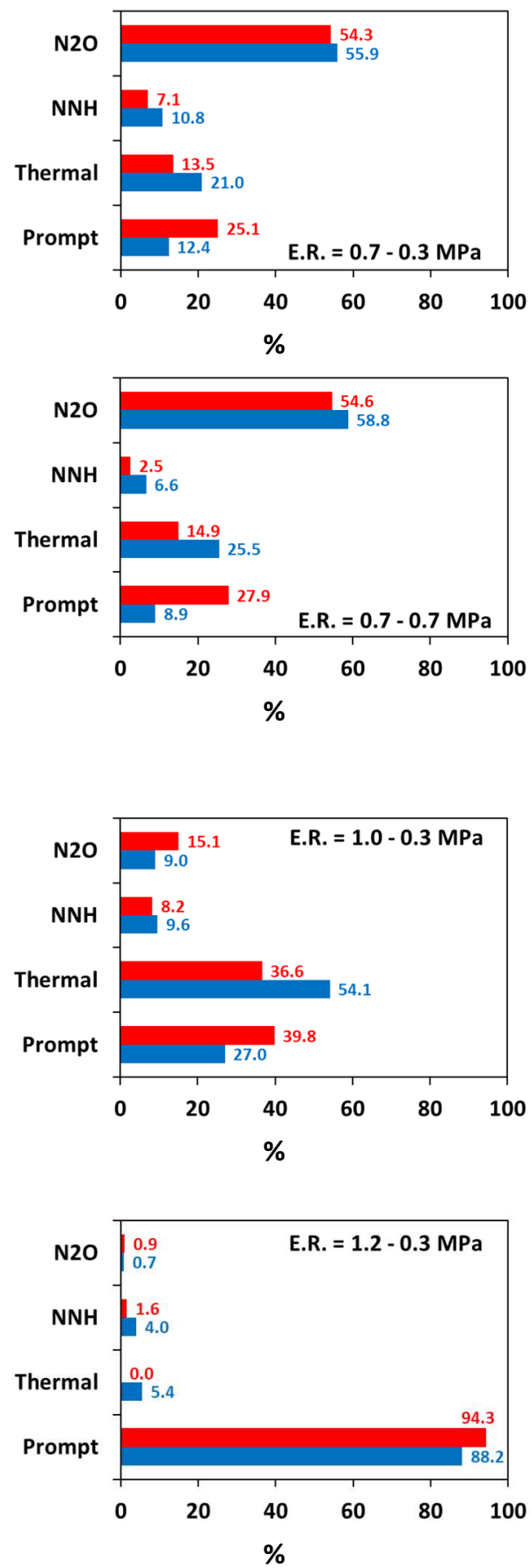

Klippenstein Mechanism

GDFkin ${ }^{\circledR 3.0 \_N o m e c h a 2.0 ~}$ 
Figure 8

a)

\section{E.R. $=0.7$}

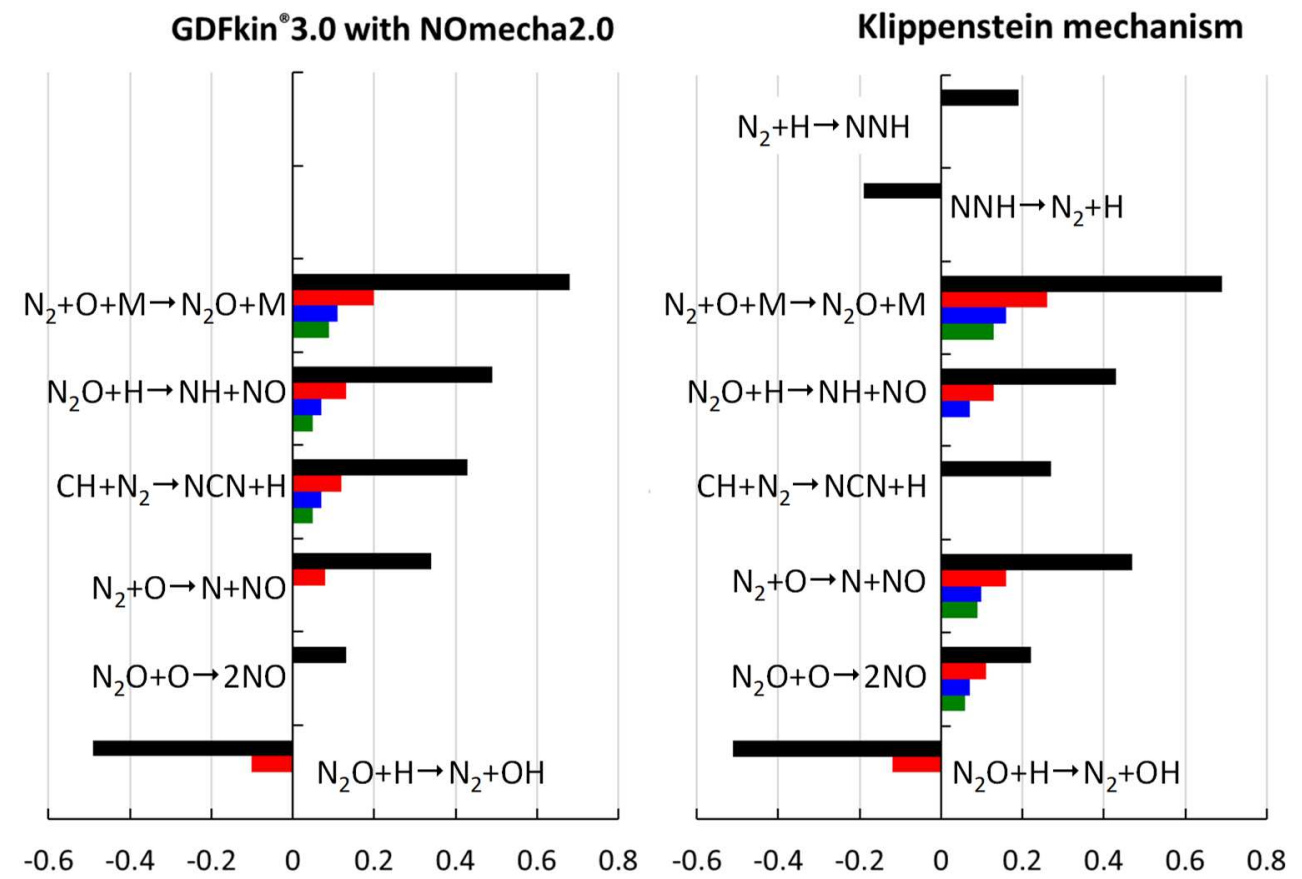

b)

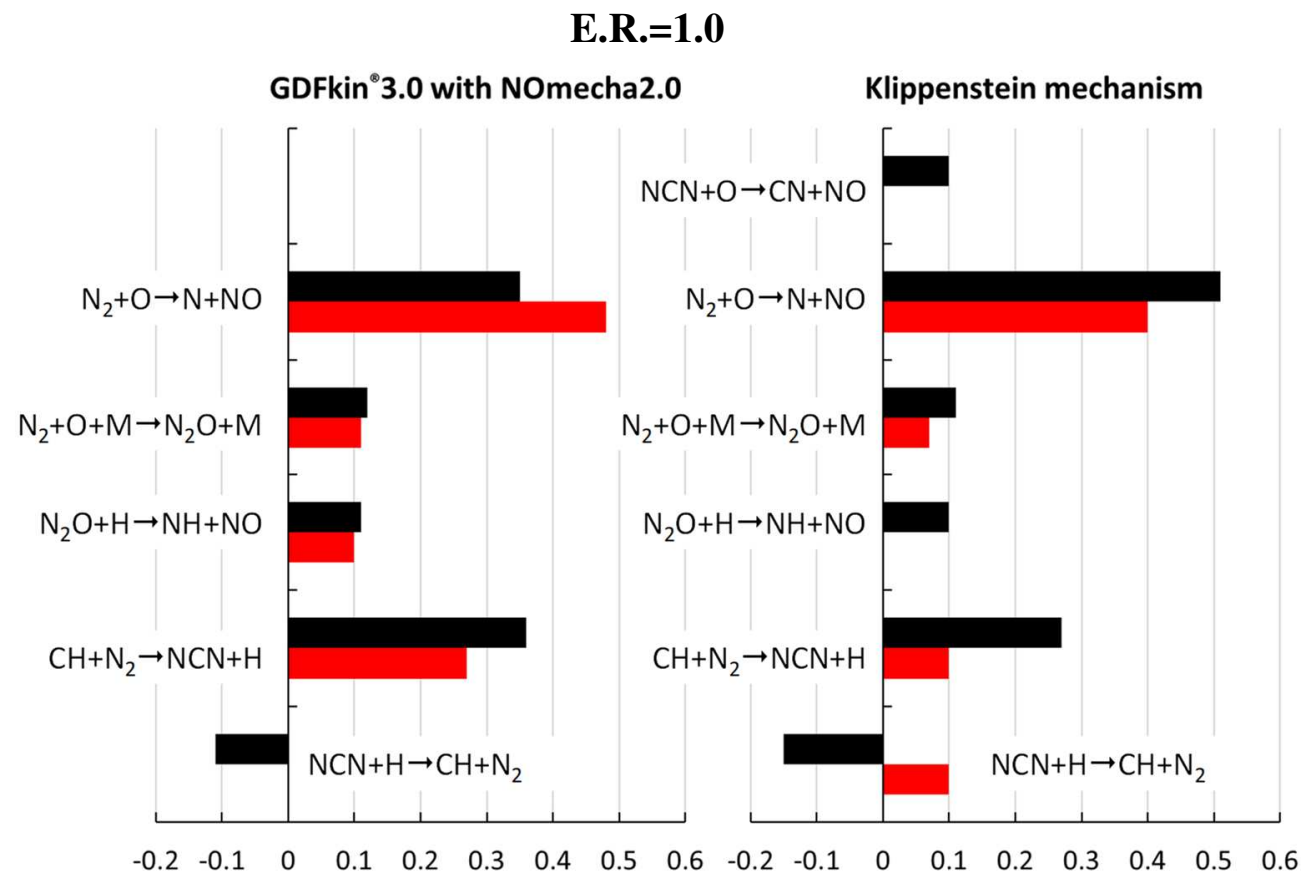

c)

$$
\text { E.R.=1.2 }
$$




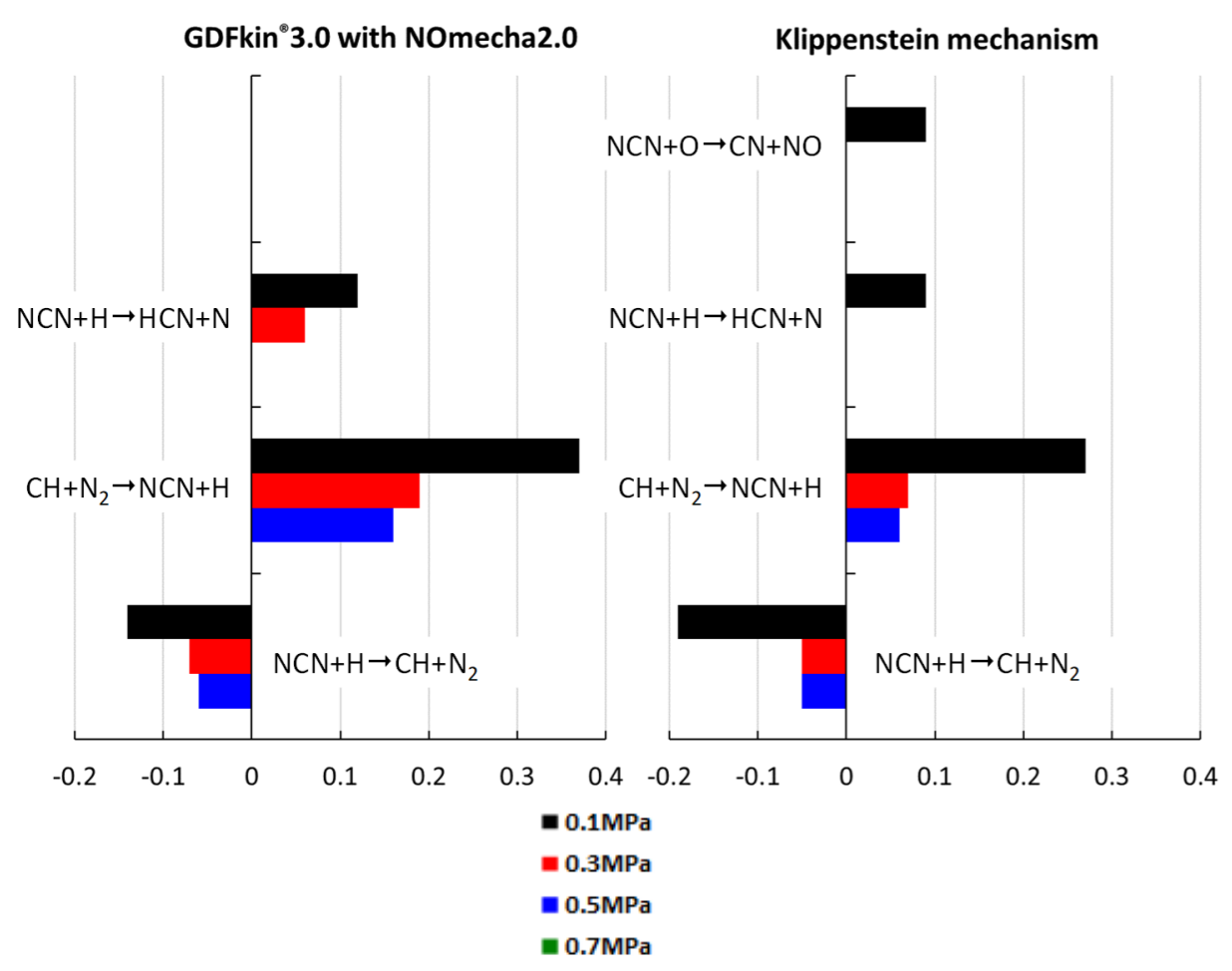




\section{Supplementary files}

Table A: Comparison between peak temperature (in K) and peak NO mole fraction (in ppm) without and with considering radiation heat loss for our lean, stoichiometric and rich flames. Calculations were carried out using LOGESOFT software together with GDFkin ${ }^{\circledR}$ 3.0_NOmecha2.0 mechanism.

\begin{tabular}{|c|c|c|c|c|c|}
\hline \multirow[b]{2}{*}{ E.R. } & \multirow{2}{*}{$\begin{array}{c}\text { Pressure } \\
(\mathrm{MPa})\end{array}$} & \multicolumn{2}{|c|}{$\begin{array}{l}\text { Peak Temperature } \\
\text { (K) }\end{array}$} & \multicolumn{2}{|c|}{$\begin{array}{c}\text { Peak NO } \\
\text { (ppm) }\end{array}$} \\
\hline & & $\begin{array}{l}\text { Without } \\
\text { radiation heat loss }\end{array}$ & \begin{tabular}{|c} 
With \\
radiation heat loss
\end{tabular} & $\begin{array}{c}\text { Without } \\
\text { radiation heat loss }\end{array}$ & $\begin{array}{c}\text { With } \\
\text { radiation heat loss }\end{array}$ \\
\hline \multirow{4}{*}{0.7} & 0.1 & 1823 & 1817 & 6.85 & 6.14 \\
\hline & 0.3 & 1859 & 1844 & 8.43 & 8.17 \\
\hline & 0.5 & 1863 & 1853 & 9.58 & 9.13 \\
\hline & 0.7 & 1863 & 1855 & 10.1 & 9.46 \\
\hline \multirow[t]{2}{*}{1} & 0.1 & 2108 & 2101 & 39.3 & 38.5 \\
\hline & 0.3 & 2241 & 2230 & 88.5 & 85.5 \\
\hline \multirow{3}{*}{1.2} & 0.1 & 2038 & 2032 & 55.1 & 54.8 \\
\hline & 0.3 & 2107 & 2097 & 76.0 & 75.4 \\
\hline & 0.5 & 2122 & 2109 & 78.2 & 77.5 \\
\hline
\end{tabular}


Table B: Reactions (and associated references) whose rate constants must be modified between the low and high pressure version of GDFkin $33.0 \_N O m e c h a 2.0$

\begin{tabular}{|c|c|}
\hline Reaction at low pressure & Reaction at high pressure \\
\hline $\mathrm{H}_{2} \mathrm{O}_{2}=\mathrm{OH}+\mathrm{OH}[1]$ & $\mathrm{OH}+\mathrm{OH}=\mathrm{H}_{2} \mathrm{O}_{2}[1]$ \\
\hline $\mathrm{CH}_{4}=\mathrm{CH}_{3}+\mathrm{H}[2]$ & $\mathrm{CH}_{3}+\mathrm{H}(+\mathrm{M})=\mathrm{CH}_{4}(+\mathrm{M})[3]$ \\
\hline $\mathrm{CH}_{3}+\mathrm{OH}=\mathrm{CH}_{2} \mathrm{OH}+\mathrm{H}[3]$ & $\mathrm{CH}_{3}+\mathrm{OH}=\mathrm{CH}_{2} \mathrm{OH}+\mathrm{H}[3]$ \\
\hline $\mathrm{CH}_{3}+\mathrm{OH}=\mathrm{CH}_{2} \mathrm{O}+\mathrm{H}_{2}[3]$ & $\mathrm{CH}_{3}+\mathrm{OH}=\mathrm{CH}_{2} \mathrm{O}+\mathrm{H}_{2}[3]$ \\
\hline $\mathrm{CH}_{3}+\mathrm{OH}=\mathrm{CH}_{3} \mathrm{O}+\mathrm{H}[3]$ & $\mathrm{CH}_{3}+\mathrm{OH}=\mathrm{CH}_{3} \mathrm{O}+\mathrm{H}[3]$ \\
\hline $\mathrm{CH}_{3}+\mathrm{OH}=\mathrm{SCH}_{2}+\mathrm{H}_{2} \mathrm{O}[4]$ & $\mathrm{CH}_{3}+\mathrm{OH}=\mathrm{SCH}_{2}+\mathrm{H}_{2} \mathrm{O}[3]$ \\
\hline $\mathrm{CH}_{3}+\mathrm{CH}_{3}=\mathrm{C}_{2} \mathrm{H}_{6}[5]$ & $\mathrm{CH}_{3}+\mathrm{CH}_{3}=\mathrm{C}_{2} \mathrm{H}_{6}[5]$ \\
\hline $\mathrm{C}_{2} \mathrm{H}_{6}=\mathrm{C}_{2} \mathrm{H}_{5}+\mathrm{H}[6]$ & $\mathrm{C}_{2} \mathrm{H}_{6}=\mathrm{C}_{2} \mathrm{H}_{5}+\mathrm{H}[6]$ \\
\hline $\mathrm{C}_{2} \mathrm{H}_{4}+\mathrm{H}=\mathrm{C}_{2} \mathrm{H}_{5}[7]$ & $\mathrm{C}_{2} \mathrm{H}_{5}=\mathrm{C}_{2} \mathrm{H}_{4}+\mathrm{H}[7]$ \\
\hline $\mathrm{HCNO}=\mathrm{HCN}+\mathrm{O}[8,9]$ & $\mathrm{HCNO}=\mathrm{HCN}+\mathrm{O}[8,9]$ \\
\hline $\mathrm{H}+\mathrm{NCN}=\mathrm{HNCN}[10]$ & $\mathrm{H}+\mathrm{NCN}=\mathrm{HNCN}[10]$ \\
\hline
\end{tabular}

[1] JPL Publication 06-2, Chemical Kinetics and Photochemical Data for Use in Atmospheric Studies, Evaluation Number 15, July 2006

[2] C.J. Cobos and J. Troe, The dissociation-recombination system $\mathrm{CH}_{4}+\mathrm{M}=\mathrm{CH}_{3}+\mathrm{H}+\mathrm{M}$ : Reevaluated experiments from 300 to 3000 K, Zeitschrift für Physikalische Chemie 167 (1990) 129.

[3] A.M. Dean, P.R. Westmoreland, Bimolecular QRRK analysis of methyl radical reactions, Int. J. Chem. Kin. 19 (3) (1987) 207-228.

[4] G.P. Smith, D.M. Golden, M. Frenklach, N.W. Moriarty, B. Eiteneer, M. Goldenberg, C.T. Bowman, R.K. Hanson, S. Song, W.C. Gardiner, V.V. Lissianski, Z. Qin Z., GRImech3.0 Mechanism (1999). http://www.me.berkeley.edu/gri_mech/

[5] D. Walter, H. H. Grotheer, J. W. Davies, M. J. Pilling, A. F. Wagner, Experimental and theoretical study of the recombination reaction $\mathrm{CH}_{3}+\mathrm{CH}_{3} \rightarrow \mathrm{C}_{2} \mathrm{H}_{6}$, Symposium (International) on Combustion, Vol. 23 (1991) 107-114. [6] P.H. Stewart, T. Rothem, D.M. Golden, Tabulation of rate constants for combustion modelling, Symposium (Intenational) on Combustion, Vol. 22 (1989) 943-952.

[7] Y. Feng, J.T. Niiranen, A. Bencsura, V.D. Knyazev, D. Gutman, and W. Tsang, Weak collision effects in the reaction $\mathrm{C}_{2} \mathrm{H}_{5}=\mathrm{C}_{2} \mathrm{H}_{4}+\mathrm{H}$, J. Phys. Chem. 97 (1993) 871-880.

[8] Z. Tian, Y. Li, L. Zhang, P. Glarborg, F. Qi, An experimental and kinetic modelling study of premixed $\mathrm{NH}_{3} / \mathrm{CH}_{4} / \mathrm{O}_{2} /$ Ar flames at low pressure, Combust. Flame 156 (2009) 1413-1426.

[9] A.M. Dean, J.W. Bozzelli, in: W.C. Gardiner Jr. (Ed.), Gas-Phase Combustion Chemistry, Springer, New York, 2000, pp. $125-343$

[10] W.S. Teng, L.V. Moskaleva, H.-L. Chen, M.C. Lin, Ab initio chemical kinetics for H+ NCN: prediction of NCN heat of formation and reaction product branching via doublet and quartet surfaces, J. Phys. Chem. A 117 (2013) 5775-5784 
Table C: Normalized sensitivity coefficients of NO to reaction rate coefficients: a) for $E . R .=0.7, b)$ for $E . R .=1, c)$ for $E . R .=1.2$, as a function of pressure for GDFkin ${ }^{\circledR} 3.0$ associated with NOmecha2.0 (in red, left column) and Klippenstein mechanism (in blue, right column).

a)

\begin{tabular}{|c|c|c|c|c|c|c|c|c|}
\hline \multirow{2}{*}{$\begin{array}{l}\text { E.R. = } 0.7 \\
\text { Reaction }\end{array}$} & \multicolumn{4}{|c|}{$\begin{array}{c}\text { GDFkin }{ }^{\circledR 3} \text { 3.0_NOmecha2.0 } \\
\text { mechanism }\end{array}$} & \multicolumn{4}{|c|}{ Klippenstein mechanism } \\
\hline & $0.1 \mathrm{MPa}$ & $0.3 \mathrm{MPa}$ & $0.5 \mathrm{MPa}$ & 0.7 MPa & $\begin{array}{c}0.1 \\
\mathrm{MPa}\end{array}$ & $\begin{array}{c}0.3 \\
\mathrm{MPa}\end{array}$ & $\begin{array}{c}0.5 \\
\mathrm{MPa}\end{array}$ & $\begin{array}{c}0.7 \\
\mathrm{MPa}\end{array}$ \\
\hline \multicolumn{9}{|c|}{ Common reactions to both mechanisms } \\
\hline $\mathrm{H}+\mathrm{O}_{2} \rightarrow \mathrm{O}+\mathrm{OH}$ & 1 & 1 & 1 & 1 & 1 & 1 & 1 & 1 \\
\hline $\mathrm{O}+\mathrm{OH} \rightarrow \mathrm{H}+\mathrm{O}_{2}$ & -0.61 & -0.28 & -0.24 & -0.21 & -0.77 & -0.28 & -0.23 & -0.2 \\
\hline $\mathrm{N}_{2} \mathrm{O}+\mathrm{H} \rightarrow \mathrm{N} 2+\mathrm{OH}$ & -0.49 & -0.1 & 0 & 0 & -0.51 & -0.12 & 0 & 0 \\
\hline $\mathrm{H}+\mathrm{O}_{2}+\mathrm{M} \rightarrow \mathrm{HO} 2+\mathrm{M}$ & -0.36 & -0.46 & -0.52 & -0.56 & -0.37 & -0.44 & -0.49 & -0.53 \\
\hline $\mathrm{H}_{2} \mathrm{O}+\mathrm{O} \rightarrow 2 \mathrm{OH}$ & -0.21 & 0.13 & 0.13 & 0.14 & -0.38 & -0.26 & -0.18 & -0.16 \\
\hline $2 \mathrm{OH} \rightarrow \mathrm{H}_{2} \mathrm{O}+\mathrm{O}$ & 0.23 & 0.12 & -0.09 & -0.08 & 0.38 & 0.23 & 0.16 & 0.14 \\
\hline $\mathrm{CO}_{2}+\mathrm{H} \rightarrow \mathrm{CO}+\mathrm{OH}$ & -0.15 & 0 & 0 & 0 & -0.19 & -0.08 & -0.07 & 0 \\
\hline $\mathrm{CO}+\mathrm{OH} \rightarrow \mathrm{CO}_{2}+\mathrm{H}$ & 0.56 & 0.40 & 0.36 & 0.34 & 0.59 & 0.40 & 0.36 & 0.33 \\
\hline $\mathrm{CH}_{3}+\mathrm{H}+\mathrm{M} \rightarrow \mathrm{CH}_{4}+\mathrm{M}$ & -0.14 & -0.19 & -0.19 & -0.18 & -0.23 & -0.24 & -0.23 & -0.21 \\
\hline $\mathrm{N}_{2} \mathrm{O}+\mathrm{O} \rightarrow 2 \mathrm{NO}$ & 0.13 & 0 & 0 & 0 & 0.22 & 0.11 & 0.07 & 0.06 \\
\hline $\mathrm{H}_{2}+\mathrm{OH} \rightarrow \mathrm{H} 2 \mathrm{O}+\mathrm{H}$ & 0.16 & 0.15 & 0.13 & 0.12 & 0.2 & 0.16 & 0.15 & 0.14 \\
\hline $\mathrm{HCO}+\mathrm{M} \rightarrow \mathrm{H}+\mathrm{CO}+\mathrm{M}$ & 0.25 & 0.23 & 0.2 & 0.18 & 0.24 & 0.24 & 0.24 & 0.24 \\
\hline $\mathrm{N}_{2}+\mathrm{O} \rightarrow \mathrm{N}+\mathrm{NO}$ & 0.34 & 0.08 & 0 & 0 & 0.47 & 0.16 & 0.1 & 0.09 \\
\hline $\mathrm{CH}+\mathrm{N}_{2} \rightarrow \mathrm{NCN}+\mathrm{H}$ & 0.43 & 0.12 & 0.07 & 0.05 & 0.27 & 0 & 0 & 0 \\
\hline $\mathrm{N}_{2} \mathrm{O}+\mathrm{H} \rightarrow \mathrm{NH}+\mathrm{NO}$ & 0.49 & 0.13 & 0.07 & 0.05 & 0.43 & 0.13 & 0.07 & 0 \\
\hline $\mathrm{N}_{2}+\mathrm{O}+\mathrm{M} \rightarrow \mathrm{N}_{2} \mathrm{O}+\mathrm{M}$ & 0.68 & 0.2 & 0.11 & 0.09 & 0.69 & 0.26 & 0.16 & 0.13 \\
\hline \multicolumn{9}{|c|}{ Different reactions between the two mechanisms } \\
\hline $\mathrm{CH}_{3}+\mathrm{O} \rightarrow \mathrm{CH}_{2} \mathrm{O}+\mathrm{H}$ & -0.31 & -0.08 & 0 & 0 & _- & _- & _- & - \\
\hline $\mathrm{CH}_{2}+\mathrm{O}_{2} \rightarrow \mathrm{CH}_{2} \mathrm{O}+\mathrm{O}$ & -0.13 & 0 & 0 & 0 & - & 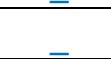 & 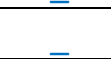 & 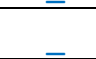 \\
\hline $\mathrm{CH}_{3}+\mathrm{OH} \rightarrow \mathrm{CH}_{2}+\mathrm{H}_{2} \mathrm{O}$ & 0.22 & 0.09 & 0.07 & 0.07 & - & $=$ & - & - \\
\hline $\mathrm{CH}_{2}+\mathrm{OH} \rightarrow \mathrm{CH}+\mathrm{H}_{2} \mathrm{O}$ & 0.29 & 0.1 & 0.06 & 0 & & & & \\
\hline $\mathrm{CH}+\mathrm{O}_{2} \rightarrow \mathrm{HCO}+\mathrm{O}$ & & & & & -0.25 & 0 & 0 & 0 \\
\hline $\mathrm{CH}_{2}+\mathrm{H} \rightarrow \mathrm{CH}+\mathrm{H}_{2}$ & & & & & 0.27 & 0 & 0 & 0 \\
\hline $\mathrm{NNH} \rightarrow \mathrm{N}_{2}+\mathrm{H}$ & & - & & & -0.19 & 0 & 0 & 0 \\
\hline $\mathrm{N}_{2}+\mathrm{H} \rightarrow \mathrm{NNH}$ & & - & 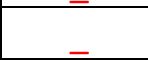 & & 0.19 & 0 & 0 & 0 \\
\hline
\end{tabular}

b)

\begin{tabular}{|c|c|c|c|c|}
\hline E.R. $=\mathbf{1}$ & \multicolumn{2}{|c|}{ GDFkin $^{{ }^{+}}$3.0_NOmecha2.0 mechanism } & \multicolumn{2}{c|}{ Klippenstein mechanism } \\
\hline Reaction & $\mathbf{0 . 1} \mathrm{MPa}$ & $\mathbf{0 . 3} \mathrm{MPa}$ & $\mathbf{0 . 1} \mathrm{MPa}$ & $\mathbf{0 . 3} \mathrm{MPa}$ \\
\hline \multicolumn{5}{|c|}{ Common reactions to both mechanisms } \\
\hline $\mathrm{H}+\mathrm{O}_{2} \rightarrow \mathrm{O}+\mathrm{OH}$ & 1 & 1 & 1 & 1 \\
\hline $\mathrm{O}+\mathrm{OH} \rightarrow \mathrm{H}+\mathrm{O}_{2}$ & -0.28 & -0.36 & -0.36 & -0.17 \\
\hline $\mathrm{CO}_{2}+\mathrm{H} \rightarrow \mathrm{CO}+\mathrm{OH}$ & -0.27 & -0.28 & -0.28 & -0.22 \\
\hline $\mathrm{CO}+\mathrm{OH} \rightarrow \mathrm{CO}_{2}+\mathrm{H}$ & 0.48 & 0.51 & 0.48 & 0.38 \\
\hline $\mathrm{CH}_{3}+\mathrm{O} \rightarrow \mathrm{CH}_{2} \mathrm{O}+\mathrm{H}$ & -0.26 & -0.15 & -0.14 & 0 \\
\hline $2 \mathrm{OH} \rightarrow \mathrm{H}_{2} \mathrm{O}+\mathrm{O}$ & -0.15 & 0.12 & 0.12 & 0.2 \\
\hline $\mathrm{H}_{2} \mathrm{O}+\mathrm{O} \rightarrow 2 \mathrm{OH}$ & 0.19 & 0.20 & -0.11 & -0.21 \\
\hline
\end{tabular}




\begin{tabular}{|c|c|c|c|c|}
\hline $\mathrm{CH}_{3}+\mathrm{H}+\mathrm{M} \rightarrow \mathrm{CH}_{4}+\mathrm{M}$ & -0.14 & -0.21 & -0.21 & 0.29 \\
\hline $\mathrm{H}_{2} \mathrm{O}+\mathrm{H} \rightarrow \mathrm{H}_{2}+\mathrm{OH}$ & -0.12 & -0.14 & -0.14 & -0.12 \\
\hline $\mathrm{H}_{2}+\mathrm{OH} \rightarrow \mathrm{H}_{2} \mathrm{O}+\mathrm{H}$ & 0.17 & 0.20 & 0.20 & 0.16 \\
\hline $\mathrm{NCN}+\mathrm{H} \rightarrow \mathrm{CH}+\mathrm{N}_{2}$ & -0.11 & 0 & -0.15 & 0.1 \\
\hline $\mathrm{CH}+\mathrm{N}_{2} \rightarrow \mathrm{NCN}+\mathrm{H}$ & 0.36 & 0.27 & 0.27 & 0.1 \\
\hline $\mathrm{N}_{2} \mathrm{O}+\mathrm{H} \rightarrow \mathrm{NH}+\mathrm{NO}$ & 0.11 & 0.1 & 0.1 & 0 \\
\hline $\mathrm{N}_{2}+\mathrm{O}+\mathrm{M} \rightarrow \mathrm{N}_{2} \mathrm{O}+\mathrm{M}$ & 0.12 & 0.11 & 0.11 & 0.07 \\
\hline $\mathrm{O}+\mathrm{H}_{2} \rightarrow \mathrm{OH}+\mathrm{H}$ & 0.14 & -0.11 & 0.12 & -0.08 \\
\hline $\mathrm{HCO}+\mathrm{M} \rightarrow \mathrm{H}+\mathrm{CO}+\mathrm{M}$ & 0.15 & 0.12 & 0.13 & 0.13 \\
\hline $\mathrm{N}_{2}+\mathrm{O} \rightarrow \mathrm{N}+\mathrm{NO}$ & 0.35 & 0.48 & 0.51 & 0.4 \\
\hline \multicolumn{5}{|c|}{ Different reactions between the two mechanisms } \\
\hline $\mathrm{CH}_{4}+\mathrm{H} \rightarrow \mathrm{CH}_{3}+\mathrm{H}_{2}$ & -0.11 & -0.14 & - & - \\
\hline $\mathrm{CH}_{3}+\mathrm{OH} \rightarrow \mathrm{CH}_{2}+\mathrm{H}_{2} \mathrm{O}$ & 0.12 & 0.1 & - & - \\
\hline $\mathrm{CH}_{2}+\mathrm{OH} \rightarrow \mathrm{CH}+\mathrm{H}_{2} \mathrm{O}$ & 0.22 & 0.13 & - & _- \\
\hline $\mathrm{CH}+\mathrm{O}_{2} \rightarrow \mathrm{HCO}+\mathrm{O}$ & - & - & -0.16 & -0.06 \\
\hline $\mathrm{NCN}+\mathrm{O} \rightarrow \mathrm{CN}+\mathrm{NO}$ & _- & - & 0.1 & 0 \\
\hline $\mathrm{CH}_{2}+\mathrm{H} \rightarrow \mathrm{CH}+\mathrm{H}_{2}$ & - & - & 0.2 & 0.09 \\
\hline
\end{tabular}

c)

\begin{tabular}{|c|c|c|c|c|c|c|}
\hline \multirow{2}{*}{$\begin{array}{l}\text { E.R. }=1.2 \\
\text { Reaction }\end{array}$} & \multicolumn{3}{|c|}{$\begin{array}{c}\text { GDFkin }^{\circledR} 3.0 \_ \text {NOmecha2.0 } \\
\text { mechanism }\end{array}$} & \multicolumn{3}{|c|}{ Klippenstein mechanism } \\
\hline & $0.1 \mathrm{MPa}$ & $0.3 \mathrm{MPa}$ & $0.5 \mathrm{MPa}$ & $0.1 \mathrm{MPa}$ & $0.3 \mathrm{MPa}$ & $0.5 \mathrm{MPa}$ \\
\hline \multicolumn{7}{|c|}{ Common reactions to both mechanisms } \\
\hline $\mathrm{CH}_{3}+\mathrm{H}+\mathrm{M} \rightarrow \mathrm{CH}_{4}+\mathrm{M}$ & -0.26 & -0.46 & -0.54 & -0.31 & -0.46 & -0.53 \\
\hline $\mathrm{CH}_{3}+\mathrm{O} \rightarrow \mathrm{CH}_{2} \mathrm{O}+\mathrm{H}$ & -0.23 & -0.09 & 0 & -0.11 & 0 & 0 \\
\hline $\mathrm{CO}_{2}+\mathrm{H} \rightarrow \mathrm{CO}+\mathrm{OH}$ & -0.18 & -0.11 & -0.09 & -0.2 & -0.16 & -0.15 \\
\hline $\mathrm{CO}+\mathrm{OH} \rightarrow \mathrm{CO}_{2}+\mathrm{H}$ & 0.25 & 0.15 & 0.12 & 0.27 & 0.21 & 0.18 \\
\hline $\mathrm{NCN}+\mathrm{H} \rightarrow \mathrm{CH}+\mathrm{N}_{2}$ & -0.14 & -0.07 & -0.06 & -0.19 & -0.05 & -0.05 \\
\hline $\mathrm{CH}+\mathrm{N}_{2} \rightarrow \mathrm{NCN}+\mathrm{H}$ & 0.37 & 0.19 & 0.16 & 0.27 & 0.07 & 0.06 \\
\hline $\mathrm{CH}_{4}+\mathrm{H} \rightarrow \mathrm{CH}_{3}+\mathrm{H}_{2}$ & -0.12 & -0.13 & -0.13 & -0.1 & -0.12 & -0.13 \\
\hline $\mathrm{OH}+\mathrm{O} \rightarrow \mathrm{H}+\mathrm{O}_{2}$ & -0.12 & 0 & 0 & -0.1 & -0.05 & 0 \\
\hline $\mathrm{H}+\mathrm{O}_{2} \rightarrow \mathrm{OH}+\mathrm{O}$ & 1 & 1 & 1 & 1 & 1 & 1 \\
\hline $\mathrm{CH}_{3}+\mathrm{OH} \rightarrow \mathrm{CH}_{2} \mathrm{OH}+\mathrm{H}$ & -0.1 & 0.11 & 0.13 & 0.07 & 0.11 & 0.12 \\
\hline $\mathrm{NCN}+\mathrm{H} \rightarrow \mathrm{HCN}+\mathrm{N}$ & 0.12 & 0.06 & 0 & 0.09 & 0 & 0 \\
\hline $\mathrm{CH}_{2}+\mathrm{H} \rightarrow \mathrm{CH}+\mathrm{H}_{2}$ & 0.13 & 0 & 0 & 0.17 & 0.06 & 0.05 \\
\hline $\mathrm{HCO}+\mathrm{M} \rightarrow \mathrm{H}+\mathrm{CO}+\mathrm{M}$ & 0.18 & 0.12 & 0.09 & 0.14 & 0.11 & 0.09 \\
\hline \multicolumn{7}{|c|}{ Different reactions between the two mechanisms } \\
\hline $\mathrm{SCH}_{2}+\mathrm{M} \rightarrow \mathrm{CH}_{2}+\mathrm{M}$ & 0.11 & 0.07 & 0.06 & - & _- & _- \\
\hline $\mathrm{CH}_{2}+\mathrm{M} \rightarrow \mathrm{SCH}_{2}+\mathrm{M}$ & -0.1 & -0.07 & -0.06 & - & _- & _- \\
\hline $\mathrm{CH}+\mathrm{H} \rightarrow \mathrm{C}+\mathrm{H}_{2}$ & -0.08 & 0 & 0 & - & _- & _- \\
\hline $\mathrm{sCH}_{2}+\mathrm{H}_{2} \mathrm{O} \rightarrow \mathrm{CH}_{3} \mathrm{OH}$ & -0.08 & -0.06 & 0 & _- & $\ldots$ & $\ldots$ \\
\hline $\mathrm{H}_{2} \mathrm{O}+\mathrm{O} \rightarrow 2 \mathrm{OH}$ & 0.11 & 0 & 0 & - & _- & - \\
\hline $\mathrm{O}+\mathrm{H}_{2} \rightarrow \mathrm{OH}+\mathrm{H}$ & 0.13 & 0 & 0 & _- & $\ldots$ & _- \\
\hline $\mathrm{CH}_{2}+\mathrm{OH} \rightarrow \mathrm{CH}+\mathrm{H}_{2} \mathrm{O}$ & 0.2 & 0.13 & 0.11 & $\ldots$ & $\ldots$ & $\ldots$ \\
\hline $\mathrm{CH}+\mathrm{O}_{2} \rightarrow \mathrm{HCO}+\mathrm{O}$ & - & - & $\ldots$ & -0.1 & 0 & 0 \\
\hline
\end{tabular}




\begin{tabular}{|c|c|c|c|c|c|c|}
\hline $\mathrm{H}_{2} \mathrm{O}+\mathrm{H} \rightarrow \mathrm{OH}+\mathrm{H}_{2}$ & - & - & - & -0.1 & 0 & 0 \\
\hline $\mathrm{OH}+\mathrm{H}_{2} \rightarrow \mathrm{H}+\mathrm{H}_{2} \mathrm{O}$ & - & - & - & 0.12 & 0 & 0 \\
\hline $\mathrm{CH}+\mathrm{H}_{2} \mathrm{O} \rightarrow \mathrm{CH} \mathrm{CH}_{2} \mathrm{O}+\mathrm{H}$ & - & - & - & -0.09 & 0 & 0 \\
\hline $\mathrm{CH}_{2} \mathrm{O}+\mathrm{H} \rightarrow \mathrm{HCO}+\mathrm{H}_{2}$ & - & - & - & -0.08 & -0.05 & 0 \\
\hline $\mathrm{CH}_{2} \mathrm{O}+\mathrm{H} \rightarrow \mathrm{H}+\mathrm{CO}+\mathrm{H}_{2}$ & - & - & - & 0.08 & 0.06 & 0.05 \\
\hline $\mathrm{NCN}+\mathrm{O} \rightarrow \mathrm{CN}+\mathrm{NO}$ & - & - & - & 0.09 & 0 & 0 \\
\hline
\end{tabular}


Figure A: Comparison between calculated temperature profiles obtained with the two mechanisms (red solid line: GDFkin ${ }^{\circledR 3.0}$ with NOmecha2.0, blue dotted line: Klippenstein mechanism) assuming the adiabatic hypothesis for $\mathrm{CH}$ //air flames: a) for E.R. $=0.7$ at pressures from $P=0.1$ to $0.7 \mathrm{MPa}$; $b$ ) for $E . R .=1.0$ at pressures from $P=0.1$ to $0.3 \mathrm{MPa} ; c$ ) for $E . R .=1.2$ at pressures from $P=0.1$ to $0.5 \mathrm{MPa}$.

a)
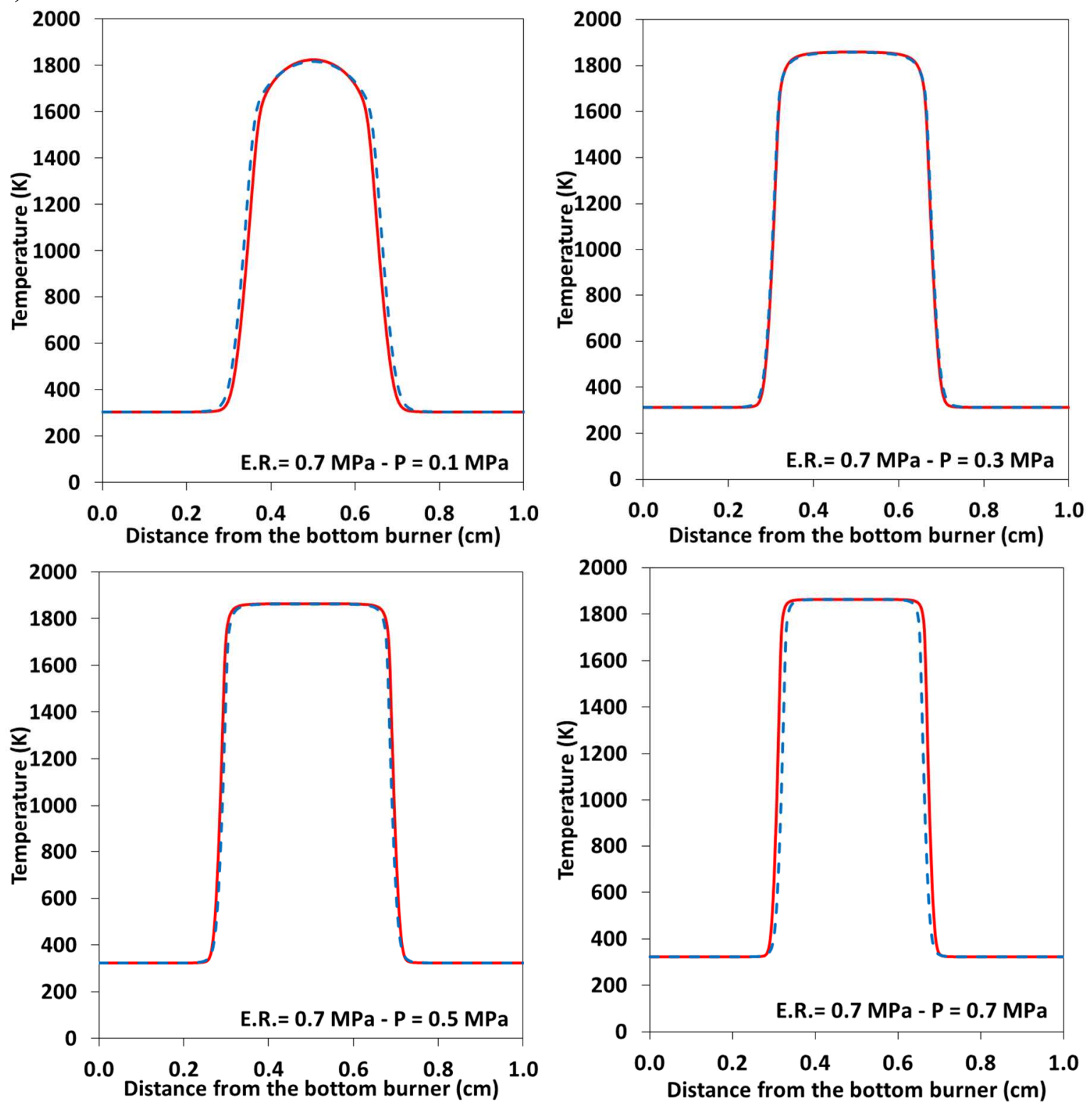

b) 

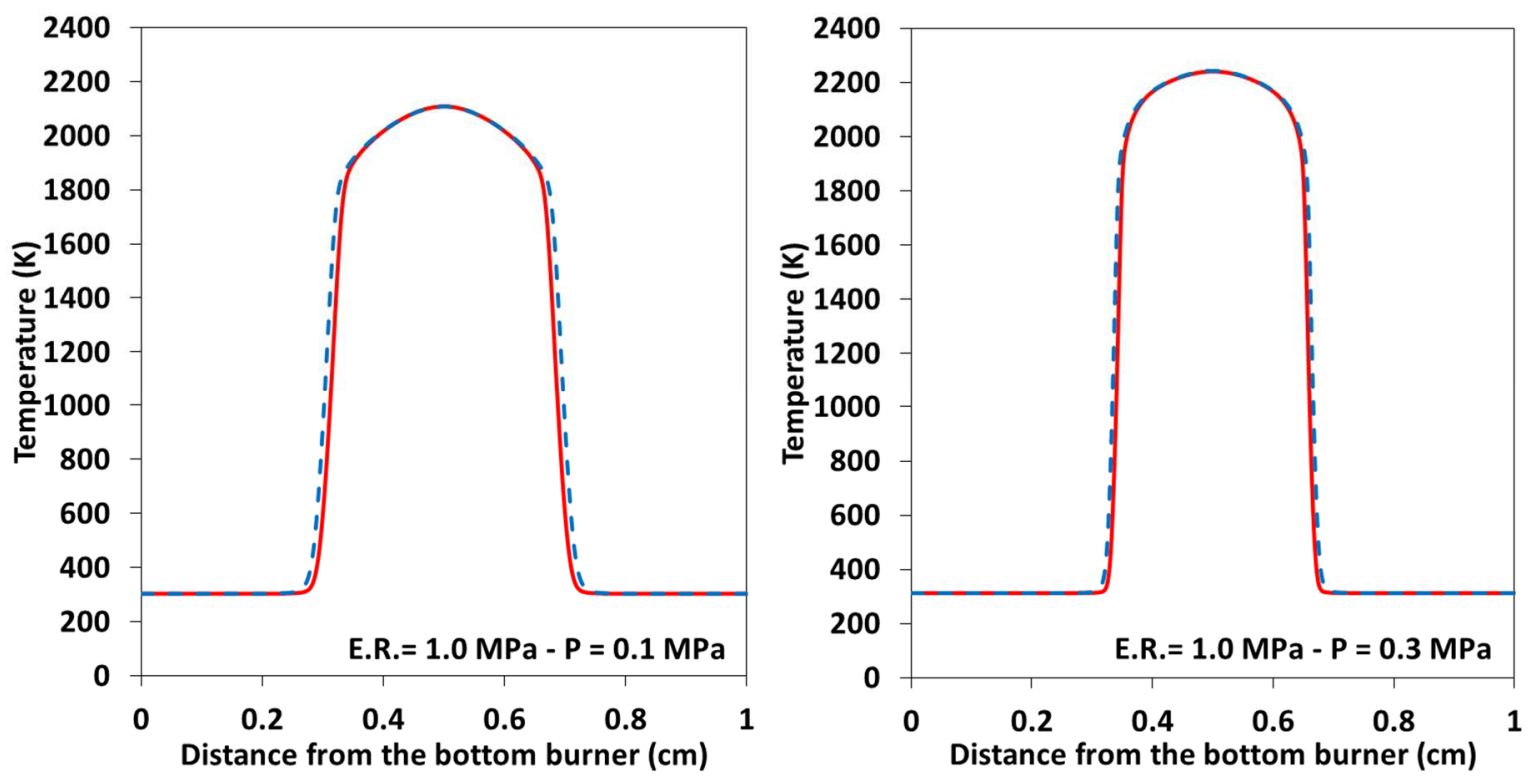

c)
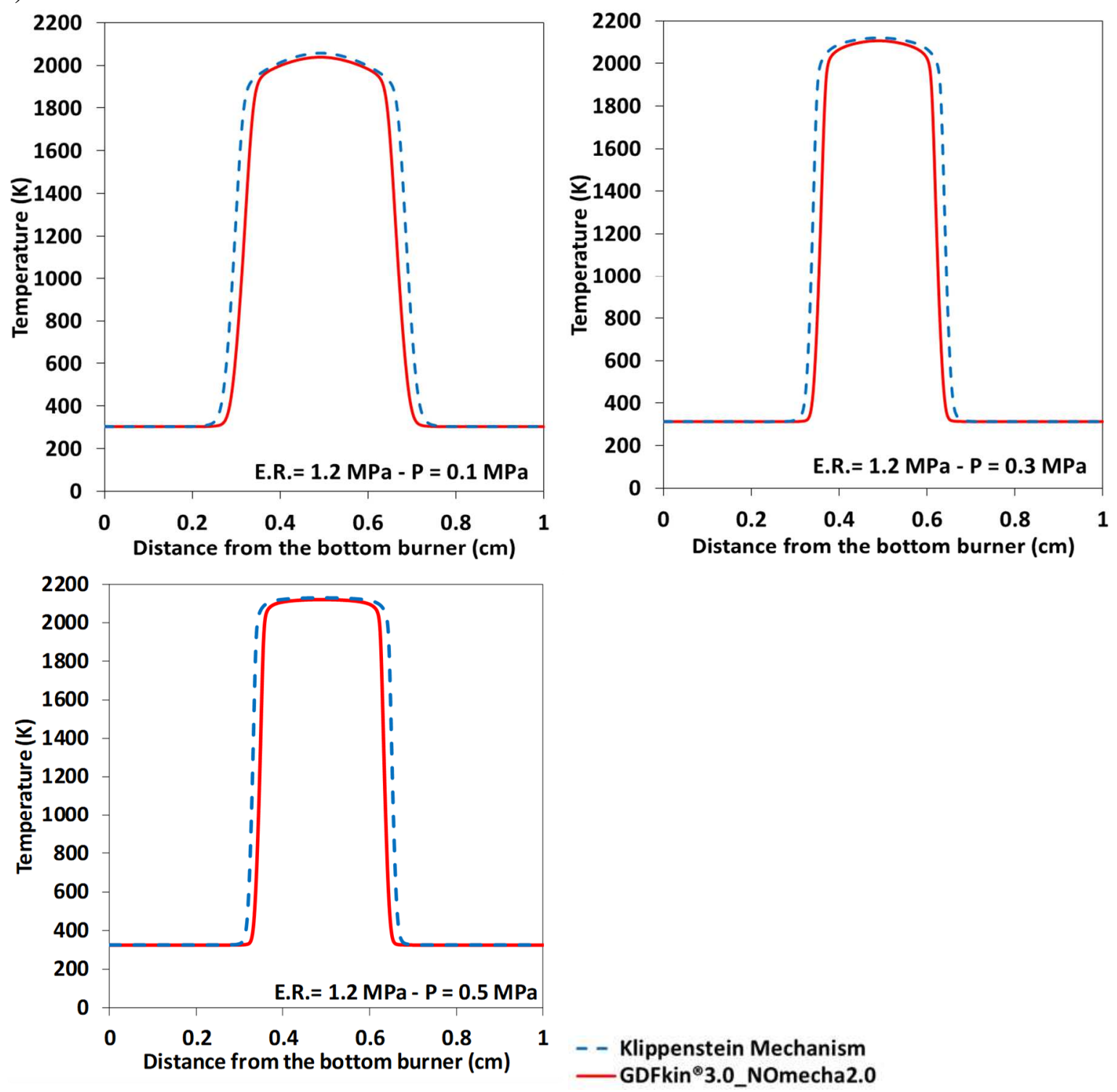
Figure B: Comparison between experimental and calculated maximum NO mole fraction $X(\mathrm{NO})_{\max }$ for $\mathrm{CH}_{4}$ /air flames: a) for $\mathrm{E} . \mathrm{R} .=0.7$ at pressures from $\mathrm{P}=0.1$ to $0.7 \mathrm{MPa}$; $b$ ) for $\mathrm{E} . \mathrm{R} .=$ 1.0 at pressures from $P=0.1$ to $0.3 \mathrm{MPa}$; ) for $E . R .=1.2$ at pressures from $P=0.1$ to $0.5 \mathrm{MPa}$. Symbols: experiments; modeling with red solid line: GDFkin ${ }^{\circledR 3} .0$ with NOmecha2.0, blue dotted line: Klippenstein mechanism.

a)

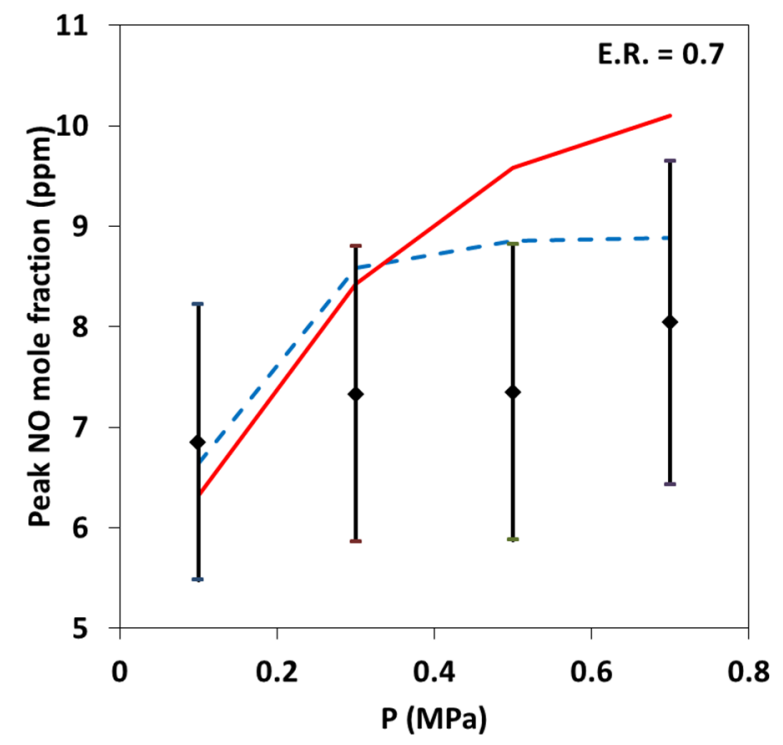

c)

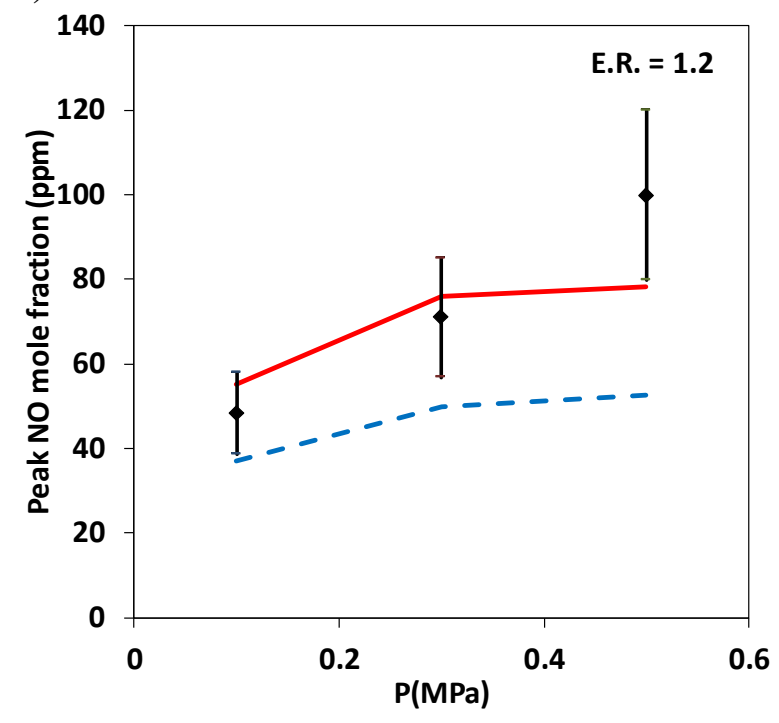

b)

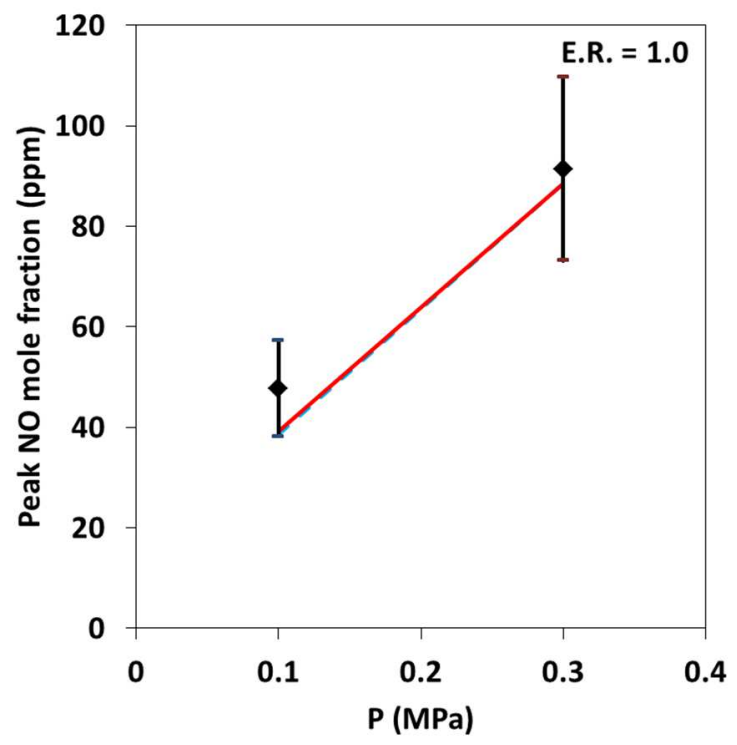

- Experimental data

- Klippenstein mechanism

-GDFkin"3.0_NOmecha2.0 
Figure C:

Comparison between experimental (obtained by Thomsen et al. $[23,24]$ ) and calculated NO number density profiles (in $\mathrm{cm}^{-3}$ ) for $\mathrm{CH}_{4}$ /air counterflow flames at $\mathrm{E} . \mathrm{R} .=0.7$ and pressures from $P=0.1$ to $0.4 \mathrm{MPa}$.

Symbols: experiments; modeling with red solid line: GDFkin ${ }^{\circledR 3} .0$ with NOmecha2.0, blue dashed line: Klippenstein mechanism.

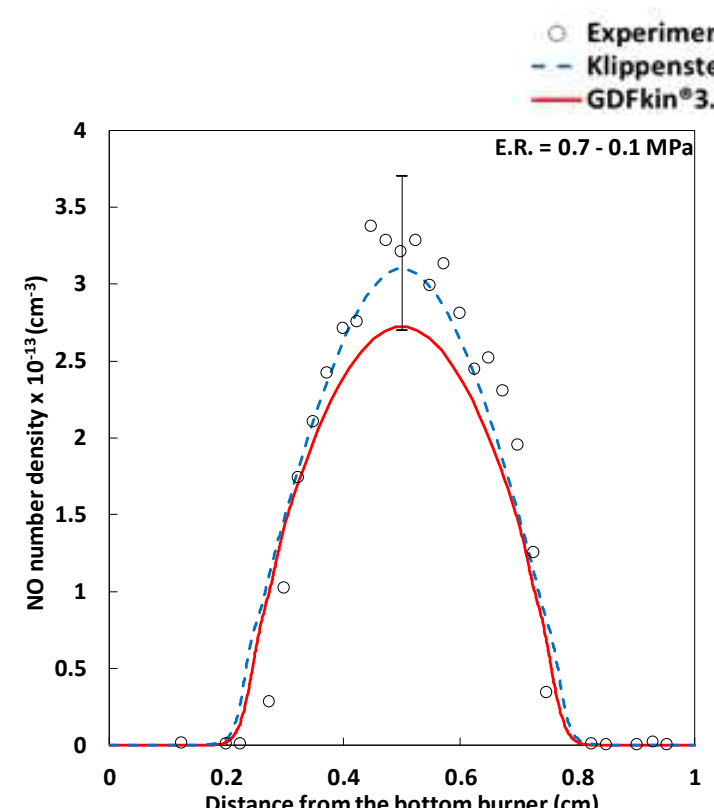

$$
\begin{aligned}
& \text { in data } \\
& \text { 0 NOmechanism } 2.0
\end{aligned}
$$
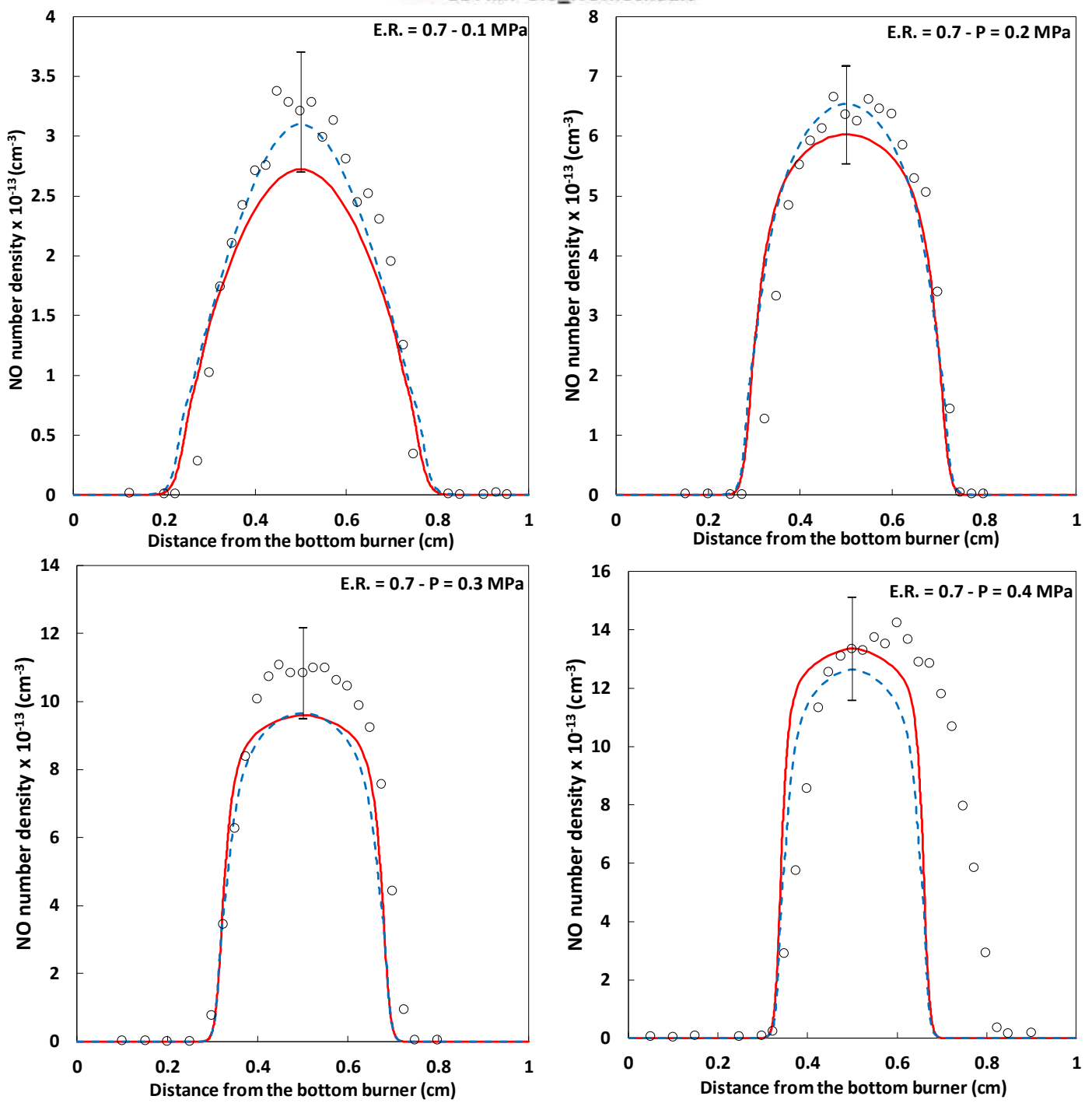
Figure D: N-species net rate diagram for E.R. $=0.7$ at $0.1 \mathrm{MPa}: 1)$ GDFkin ${ }^{\circledR 3} .0$ with NOmecha2.0; 2) Klippenstein mechanism. For clarity reasons, net rates are expressed in \% and the diagram was simplified by removing negligible pathways $(<10 \%)$

1)

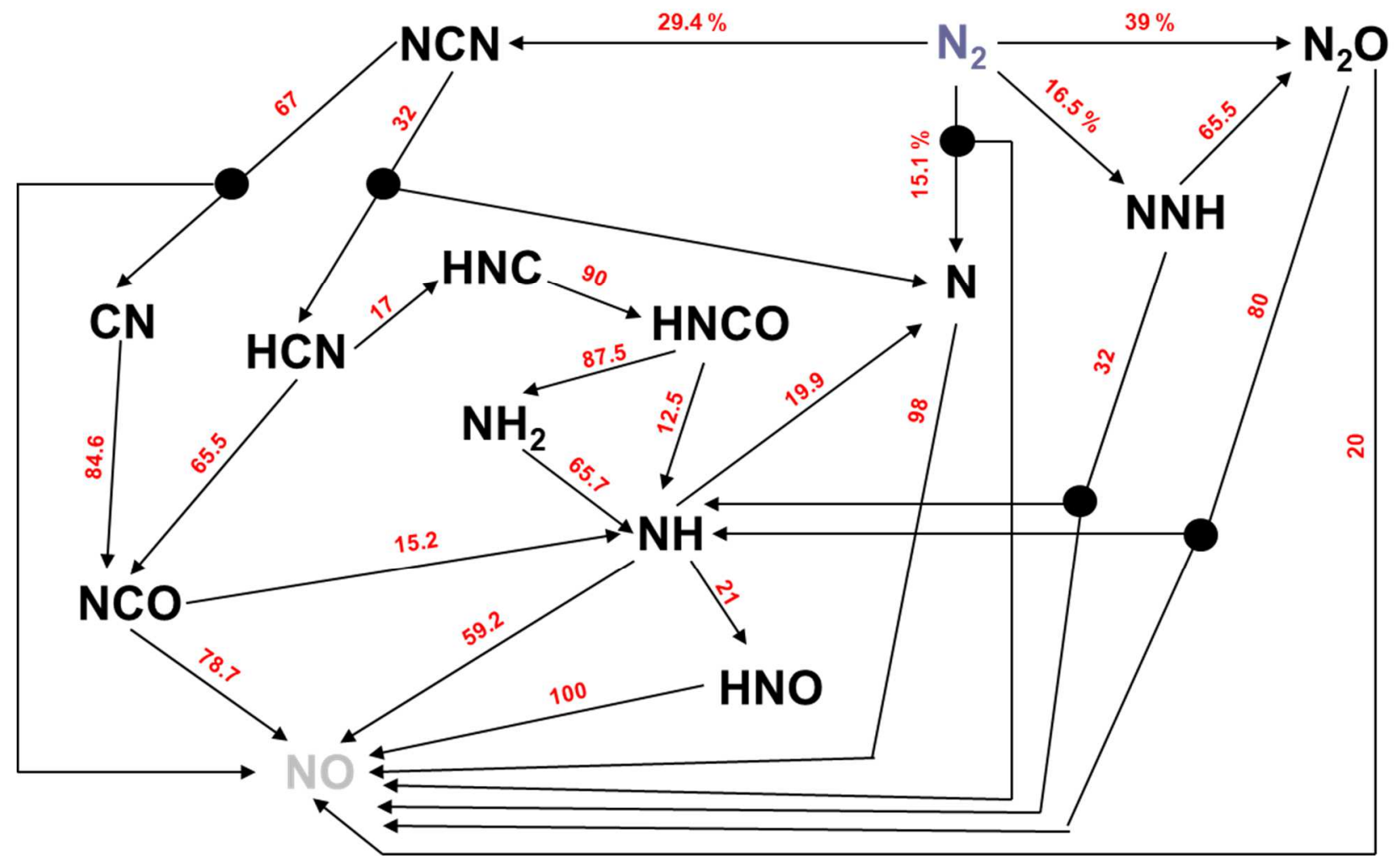

2)

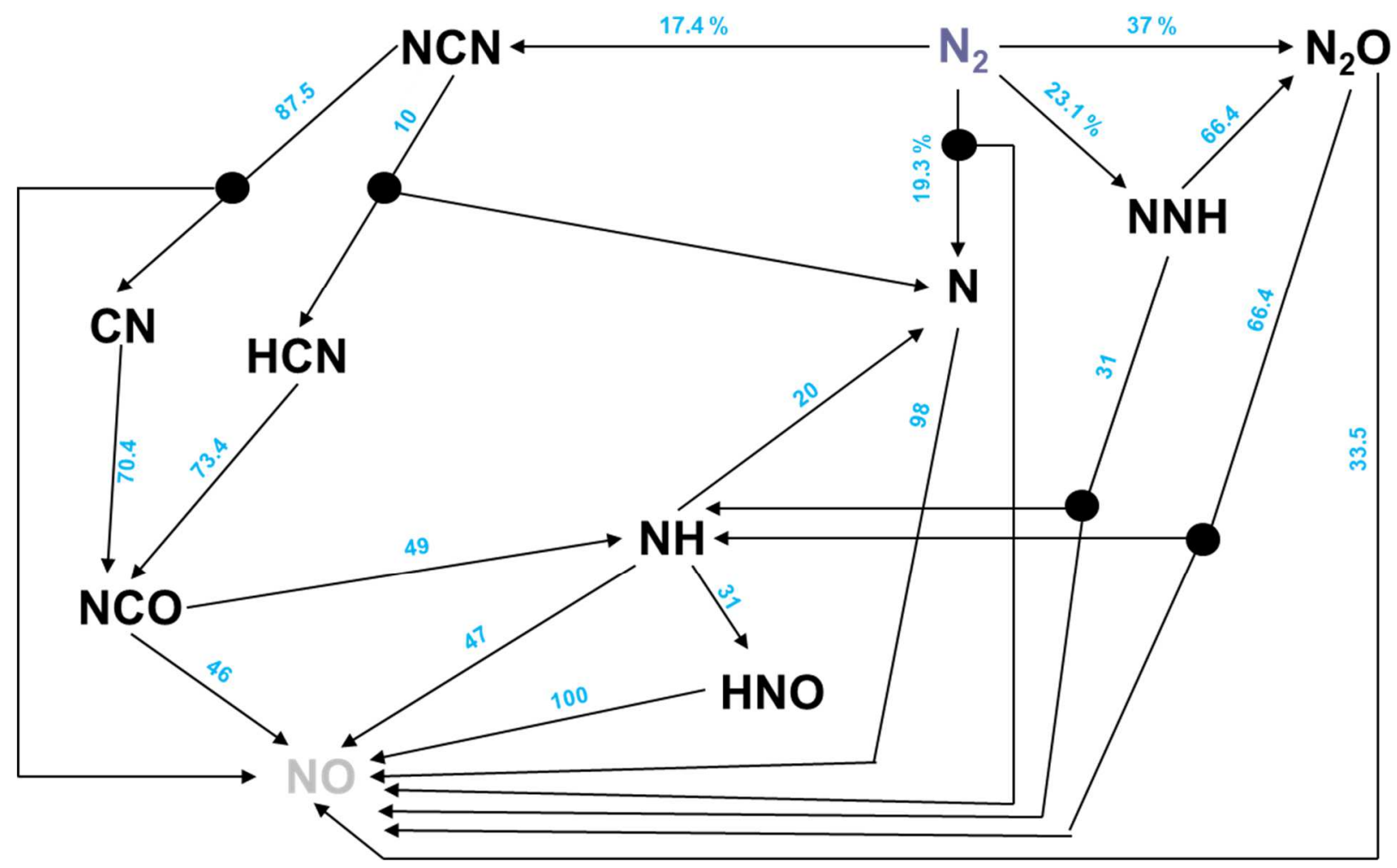


